Article

\title{
Asymmetric Synthesis of the C15-C32 Fragment of Alotamide and Determination of the Relative Stereochemistry
}

\author{
Hao-yun Shi ${ }^{1,2}$, Yang Xie ${ }^{1}$, Pei Hu ${ }^{1}$, Zi-qiong Guo ${ }^{1,2}$, Yi-hong Lu ${ }^{1,2}$, Yu Gao ${ }^{1, *}$ and \\ Cheng-gang Huang $1,2, *$ \\ 1 Shanghai Institute of Materia Medica, Chinese Academy of Sciences, 501 Haike Road, Shanghai 201203, \\ China; baiyinyun@hotmail.com (H.-y.S.), sunshine_xie@163.com (Y.X.); hupeishtcm@126.com (P.H.); \\ 18673675362@163.com (Z.-q.G.); xiong1743771101@163.com (Y.-h.L.) \\ 2 School of Pharmacy, University of Chinese Academy of Sciences, No. 19A Yuquan Road, \\ Beijing 100049, China \\ * $\quad$ Corresponding: gaoyucpu@126.com (Y.G.); cghsimm@126.com (C.-g.H.); Tel.: +86-21-2023-1963 (Y.G.)
}

Received: 15 October 2018; Accepted: 24 October 2018; Published: 30 October 2018 updates

\begin{abstract}
Alotamide is a cyclic depsipetide isolated from a marine cyanobacterium and possesses a unique activation of calcium influx in murine cerebrocortical neurons ( $\left.\mathrm{EC}_{50} 4.18 \mu \mathrm{M}\right)$. Due to its limited source, the three stereocenters (C19, C28, and C30) in its polyketide fragment remain undetermined. In this study, the first asymmetric synthesis of its polyketide fragment was achieved. Four relative possible diastereomers were constructed with a boron-mediated enantioselective aldol reaction and Julia-Kocienski olefination as the key steps. Comparison of ${ }^{13} \mathrm{C} \mathrm{NMR}$ spectra revealed the relative structure of fragment $\mathrm{C} 15-\mathrm{C} 32$ of alotamide.
\end{abstract}

Keywords: alotamide; asymmetric synthesis; relative structural determination

\section{Introduction}

Recently, several active secondary metabolites have been isolated from marine cyanobacterium and some of these metabolites demonstrate excellent bioactivities such as cytotoxic, antimicrobial, and antiprotozoal properties [1,2]. For example, apratoxins display potent cytotoxicity against several cancer cells at the nanoscale level and have become the new lead compounds in anticancer drug discovery [3-6].

Alotamide was also isolated from the marine cyanobacterium Lyngbya bouillonii in 2009 [7]. It is a cyclic depsipeptide and structurally has two parts. The northern part is a tripetide that consists of $\mathrm{N}-\mathrm{Me}-\mathrm{Val}$, Cys-derived thiazolene ring, and Pro and the southern part is a special unsaturated polyketide with three undetermined stereocenters (C19, C28, and C30). Functionally, alotamide is a unique calcium influx activator in murine cerebrocortical neurons $\left(\mathrm{EC}_{50} 4.18 \mu \mathrm{M}\right)$. Given that calcium overload is involved in physiological processes and may lead to several nervous diseases such as AD and epilepsy, this compound has gained increasing attention as a new neurotoxin from the marine resource [8]. In view of the limited natural source, a concise synthetic strategy of alotamide should be developed. In this study, we described the first asymmetric synthesis of its polyketide fragment C15-C32 and obtained four possible diastereomers. The relative stereochemistry was assigned after the NMR comparison. 
<smiles>COC(C)CC(C/C(C)=C/C=C/CC(C)/C=C(/P)C(=O)N1CCCC1c1csc(C(=O)N(C)C(=O)C(C)C)n1)OC</smiles>

Alotamide (A)<smiles>[Z6]OC(C)C/C(C)=C/C=C/C[C@@H](C)/C=C(\C)C(=O)OC</smiles>

C15-C32 fragment

Figure 1. Structure of alotamide.

\section{Results}

The chemical structure of alotamide is shown in Figure 1. The southern polyketide with three undetermined stereocenters established eight possible isomers and only four needed to be evaluated for relative stereochemical determination. In this regard, we set C19 as $R$ and listed four diastereomers, which are shown in Figure 2 (1a-1d).<smiles>C=CCOC(=O)/C(C)=C/[C@H](C)C/C=C/C=C(\C)C[C@@H](O)C[C@H](C)OC</smiles>

1a $19 R, 28 R, 30 S$<smiles>C=CCOC(=O)/C(C)=C/[C@H](C)C/C=C/C=C(\C)C[C@@H](O)C[C@@H](C)OC</smiles>

1c $19 R, 28 S, 30 R$<smiles>C=CCOC(=O)/C(C)=C/[C@H](C)C/C=C/C=C(\C)C[C@@H](O)C[C@@H](C)OC</smiles>

1b $19 R, 28 R, 30 R$<smiles>C=CCOC(=O)/C(C)=C/[C@H](C)C/C=C/C=C(\C)C[C@@H](O)C[C@@H](C)OC</smiles>

1d $19 R, 28 S, 30 S$

Figure 2. Structures of four diastereomers 1a-1d.

According to the retrosynthetic analysis (Scheme 1), the dihydroxy unit would arise from an asymmetric aldol reaction and the Julia-Kocienski olefination would be applied to form the diene part. The polyketide fragment would be separated into two subunits, 2 and 3, which both could be prepared from commercial compounds.

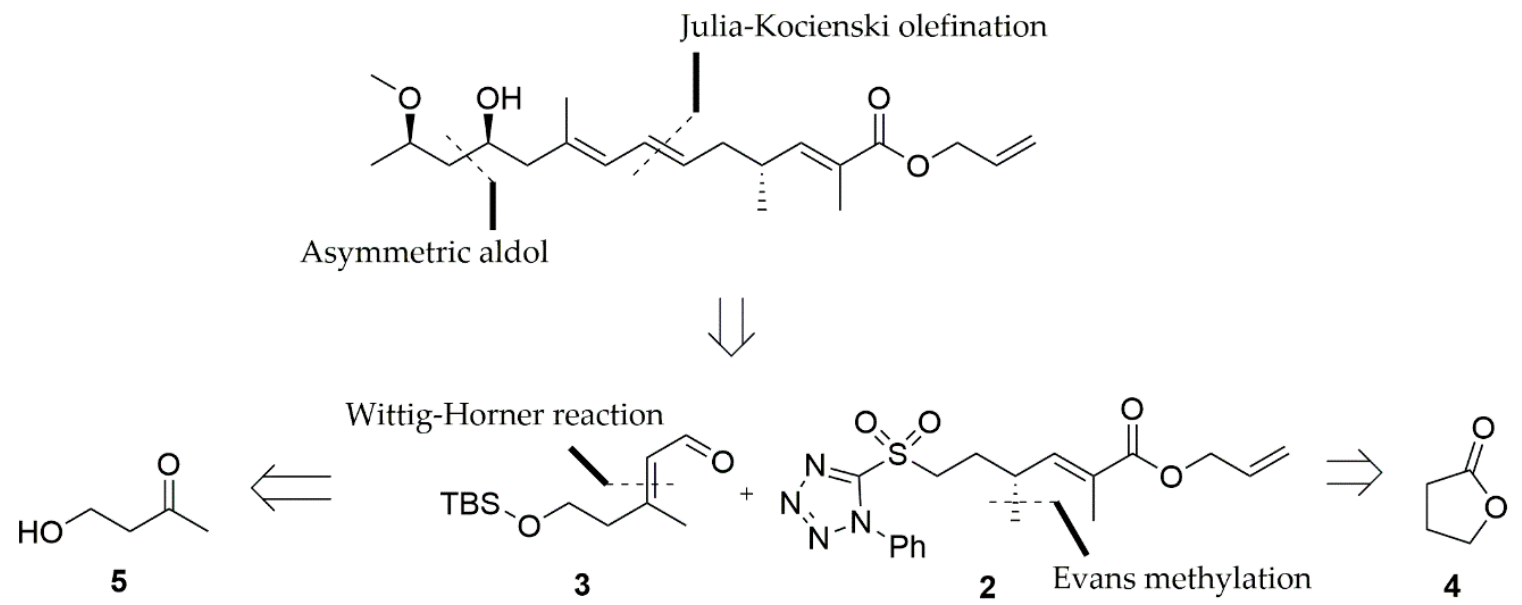

Scheme 1. Retrosynthetic analysis. 
Compound 2 was prepared from commercial lactone 4 and treated with $\mathrm{LiOH}$ to open the lactone ring (Scheme 2) [9]. The resulting compound was subjected to TBS protection and condensation with Evan's protocol 6 [10] in sequence to obtain 7 in $71 \%$ yield over three steps. Compound 7 was treated with NaHMDS/MeI at $-78{ }^{\circ} \mathrm{C}$ to obtain the desired $R$-methyl 8 in $89 \%$ yield $(\mathrm{dr}=12: 1)$. After the reduction of 8 by LiBH 4 [11], alcohol 9 was oxidized into the corresponding aldehyde, which was immediately refluxed with the Wittig reagent 10 to generate olefin $\mathbf{1 1}$. In this reaction, the $E / Z$ selectivity reached 30:1 and the little $Z$ isomer was separated in the following DIBAL-H reduction. The sequential oxidation with IBX and Pinnick reaction generated a free acid and the allyl protection was conducted to acquire $\mathbf{1 2}$ in $64 \%$ yield for the above four steps. After the deprotection of the TBS group, the Mitsunobu reaction was applied to convert the compound 13 into tetrazole 15 in $94 \%$ yield. Then the SPT part was oxidized by $\mathrm{H}_{2} \mathrm{O}_{2}(20 \mathrm{eq})$ in the presence of $\left(\mathrm{NH}_{4}\right)_{6} \mathrm{Mo}_{7} \mathrm{O}_{24}(0.2 \mathrm{eq})$ to obtain the desired 2 without the $\mathrm{Z}$ isomer [12].<smiles>O=C1CCCO1</smiles>

4

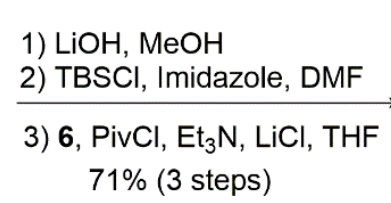
$71 \%$ (3 steps)

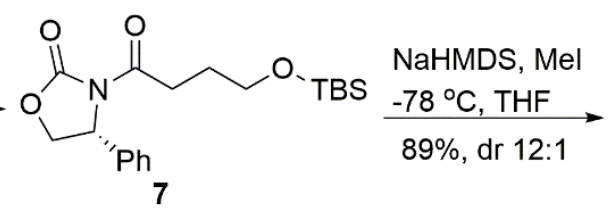<smiles>CCCCCCOCCC(C)C(=O)N1C(=O)OC[C@H]1Pc1ccccc1</smiles>

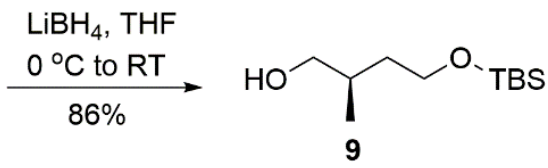

1) IBX, DMSO, $40^{\circ} \mathrm{C}$

2) 10 , toluene, $80^{\circ} \mathrm{C}$ $75 \%$ (2 steps)<smiles>CCOC(=O)/C=C(\C)CCO[13CH3]</smiles>
1) DIBAL-H, DCM, $-78^{\circ} \mathrm{C}$
2) IBX, DMSO, $40^{\circ} \mathrm{C}$
3) $\mathrm{NaClO}_{2}, \mathrm{NaH}_{2} \mathrm{PO}_{4}$ 2-methyl-2-butene t $\mathrm{BuOH} / \mathrm{H}_{2} \mathrm{O}$

4) AllylBr, $\mathrm{K}_{2} \mathrm{CO}_{3}$, DMF $64 \%$ (4 steps)

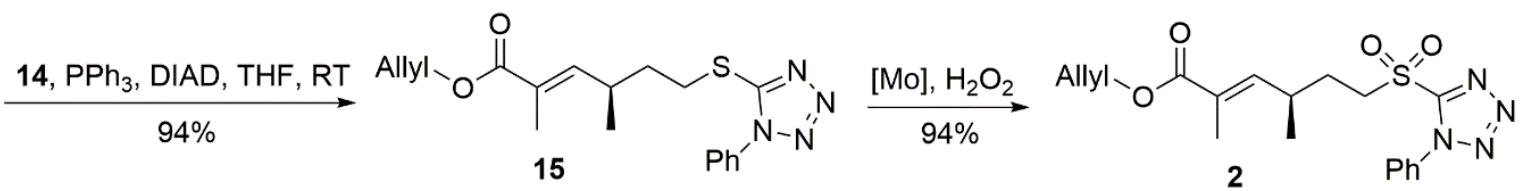<smiles>O=C1NC(c2ccccc2)CO1</smiles><smiles>CCOC(=O)C(C)P(=O)(c1ccccc1)c1ccccc1</smiles><smiles>Sc1nnnn1-c1ccccc1</smiles>

Scheme 2. Synthesis of subunit 2.

The preparation of subunit 3 was initiated with 4-hydroxy-2-butanone (Scheme 3). The Wittig-Horner reaction was conducted after PMB protection to smoothly obtain the desired product $17(70 \%$ yield, $E / Z=3: 1)$ while a complex mixture appeared when TBS protected alcohol was applied in this HWE reaction [13,14]. After the removal of the PMB group followed by the TBS protection, compound 19 was obtained and then converted into the corresponding aldehyde 3 by sequential steps of DIBAL-H reduction and IBX oxidation prior to the Julia-Kocienski olefination. 

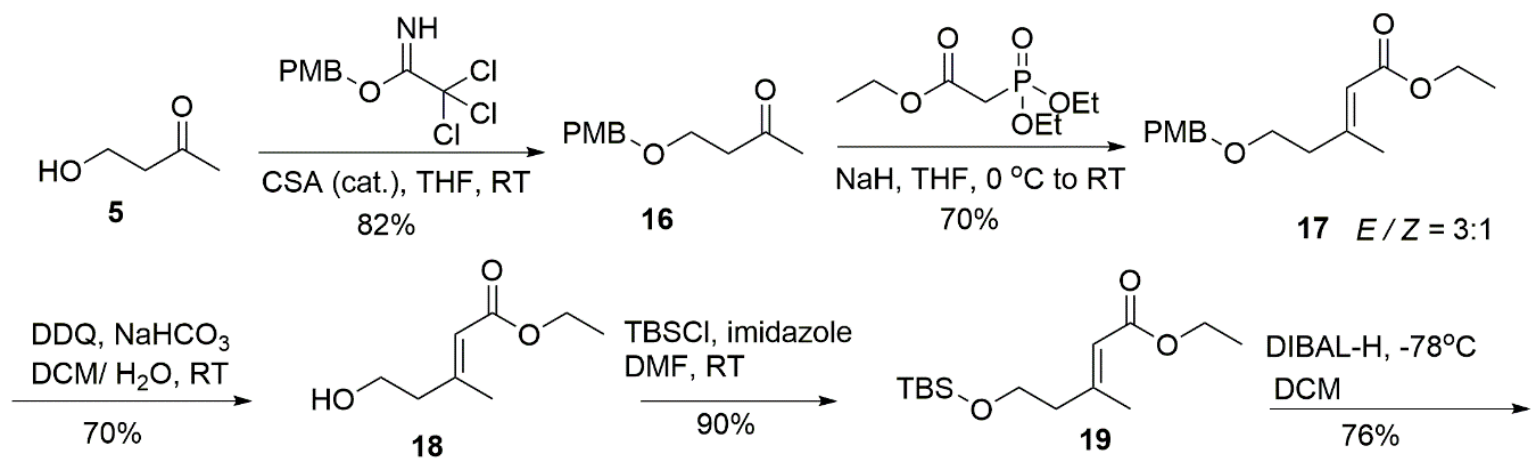

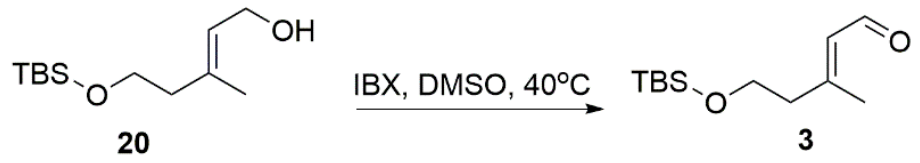

Scheme 3. Synthesis of subunit 3.

The different bases were tested through olefination (Table 1). When 1 eq KHMDS (entry 1) was applied, the yield was $50 \%$ and numerous reactants 2 and 3 remained. The product diene was an $E / Z$ mixture with $E / Z$ selectivity of up to $15: 1$. When the amount of KHMDS was increased to 1.5 eq, the yield improved and the two reactants remained in small quantities. When 2 eq KHMDS was used, the two reactants were completely consumed and the yield reached $86 \%$ while the high selectivity $(15: 1)$ was maintained. Other bases such as LiHMDS were also tried, but the resulting E/Z selectivity was low. We also exchanged the aldehyde and $\mathrm{SO}_{2} \mathrm{PT}$ functional groups and subjected them to olefination (entry 5). The yield of the $Z$ isomer greatly increased and the selectivity was 1.5:1 [15,16].

Table 1. Optimization of the Julia-Kocienski olefination.<smiles>[R]C=C(C)CCO[AsH2]</smiles>

3<smiles>C1C[AsH2]C1</smiles><smiles>[R]CCC(C)/C=C(\C)C(=O)OI</smiles>
2<smiles>COC(=O)C(C)=CC(C)CCC=CC(C)=O</smiles>
21a<smiles>[C+]1C[AsH2]C1</smiles><smiles>COCC/C(C)=C/C=C\C[C@H](C)/C=C(\C)C(=O)O[Na]</smiles>

21b

\begin{tabular}{cccccc}
\hline Entry & $\mathbf{R ~ 1}$ & $\mathbf{R} 2$ & Base (equiv) & Yield $^{\mathbf{1}}$ & 21a:21b $^{\mathbf{2}}$ \\
\hline 1 & $\mathrm{CHO}$ & $\mathrm{SO}_{2} \mathrm{PT}$ & KHMDS (1eq) & $50 \%$ & $15: 1$ \\
2 & $\mathrm{CHO}$ & $\mathrm{SO}_{2} \mathrm{PT}$ & KHMDS (1.5eq) & $72 \%$ & $15: 1$ \\
3 & $\mathrm{CHO}$ & $\mathrm{SO}_{2} \mathrm{PT}$ & KHMDS (2eq) & $86 \%$ & $15: 1$ \\
4 & $\mathrm{CHO}$ & $\mathrm{SO}_{2} \mathrm{PT}$ & LiHMDS (2eq) & $83 \%$ & $3.5: 1$ \\
5 & $\mathrm{SO}_{2} \mathrm{PT}$ & $\mathrm{CHO}$ & KHMDS (2eq) & $94 \%$ & $1.5: 1$ \\
\hline
\end{tabular}

${ }^{1}$ Combined yield of 21a and 21b. ${ }^{2}$ Determined by LC-MS.

Having completed the construction of diene 21a, we started to prepare the dihydroxy unit (Scheme 4). To our delight, under the condition of the HF/Py complex, we fairly achieved the alcohol 22 and oxidized it to corresponding aldehyde 23 by DMP prior to the aldol reaction (deprotection of PMB group in this step led to a complex mixture). 


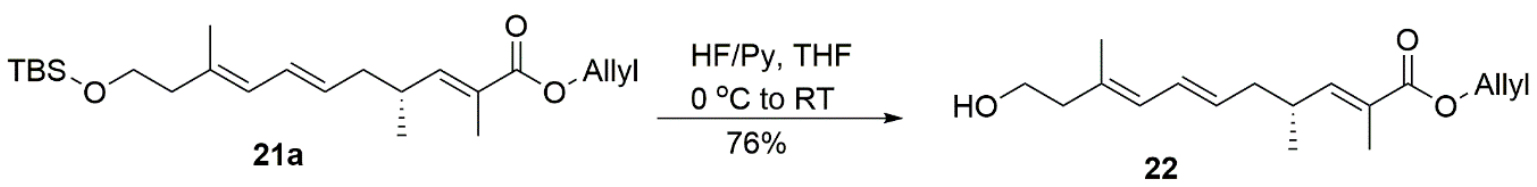

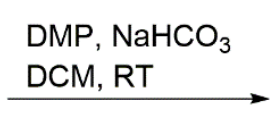<smiles>COC(=O)C(C)=CC=CCC(C)C</smiles>

23

Scheme 4. Synthesis of compound 23.

IPCBCl-controlled aldol reaction $[17,18]$ was selected to install the C28 stereo-center (Table 2). The application of (-)-IPCBCl at $-20{ }^{\circ} \mathrm{C}$ successfully generated $24 \mathbf{b}$ with the $\mathrm{C} 28(S)$ configuration in $59 \%$ yield $(\mathrm{dr}=99: 1)$. The chiral reactant was changed into (+)-IPCBCl, which afforded the C28 $(R)$ product as expected and maintained the high diastereoselectivity $(\mathrm{dr}=98: 2)$. LiHMDS also proceeded and a 1:1 mixture was obtained in this aldol reaction.

Table 2. Boron-mediated aldol reaction.<smiles>CC(=CC=CCC(C)C=C(C)C(=O)O[Na])CC=O</smiles><smiles>CCOc1ccccc1OCCOCCOCCOCCOC</smiles><smiles>C=CCOC(=O)/C(C)=C/[C@H](C)C/C=C/C=C(\C)C[C@H](O)CC(C)=O</smiles>

23 $-78^{\circ} \mathrm{C}$ to $-20^{\circ} \mathrm{C}$<smiles>C=CCOC(=O)/C(C)=C/[C@H](C)C/C=C/C=C(\C)CC(O)CC(C)=O</smiles>

\begin{tabular}{cccc}
\hline Entry & Reagent $\mathbf{A}$ & Yield $^{\mathbf{1}}$ & 24a:24b $^{\mathbf{2}}$ \\
\hline 1 & $(-)-\mathrm{IPCBCl}$ & $59 \%$ & $1: 99$ \\
2 & (+)-IPCBCl & $55 \%$ & $98: 2$ \\
3 & LiHMDS & $47 \%$ & $1: 1$ \\
\hline
\end{tabular}

${ }^{1}$ Combined yield of $\mathbf{2 4 a}$ and $\mathbf{2 4 b} .{ }^{2}$ Determined by LC-MS.

After TBS protection followed by the reduction of the combination of $\mathrm{BH}_{3}$-DMS and CBS catalysts, we obtained 26a $\left(\mathrm{dr}=4: 1\right.$, determined by $\left.{ }^{1} \mathrm{H} \mathrm{NMR}\right)$ and $\mathbf{2 6 \mathbf { b }}\left(\mathrm{dr}=17: 1\right.$, determined by $\left.{ }^{1} \mathrm{H} \mathrm{NMR}\right)$, respectively. Compounds 26c $\left(\mathrm{dr}=3.6: 1\right.$, determined by $\left.{ }^{1} \mathrm{H} N M R\right)$ and $26 \mathrm{~d}(\mathrm{dr}=14: 1$, determined by ${ }^{1} \mathrm{H}$ NMR) were achieved from $\mathbf{2 5 b}$ with the similar dr value (Scheme 5).

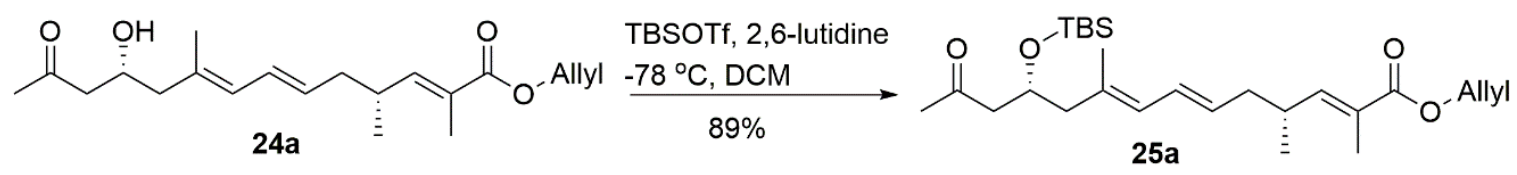

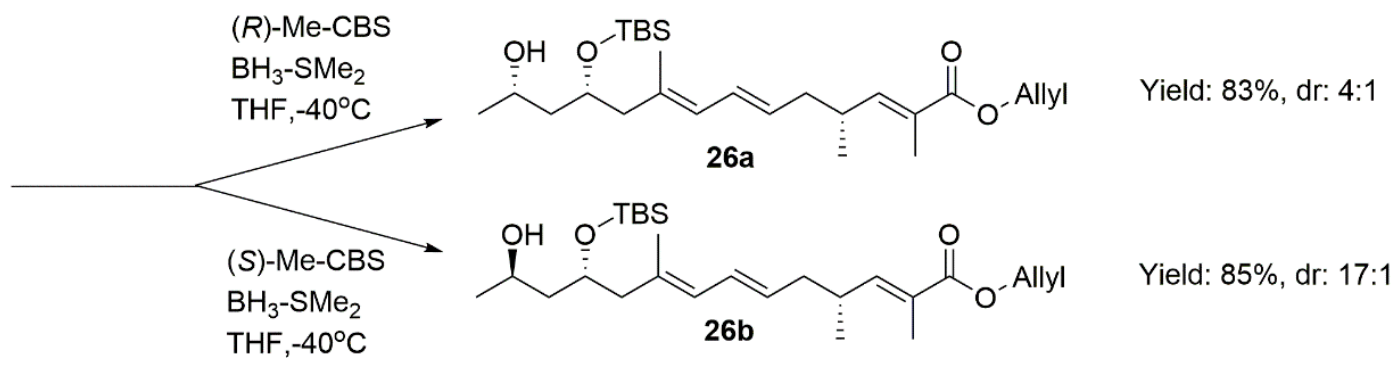

Scheme 5. Cont. 


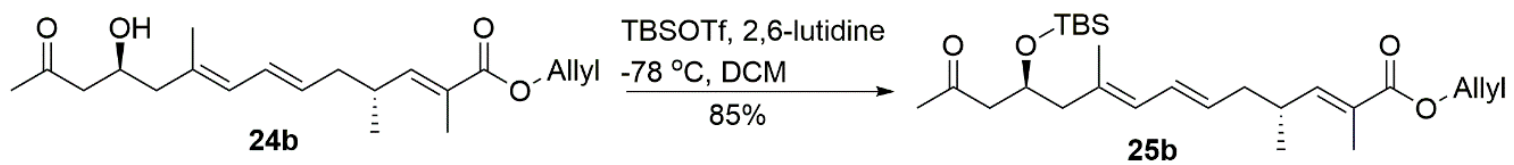

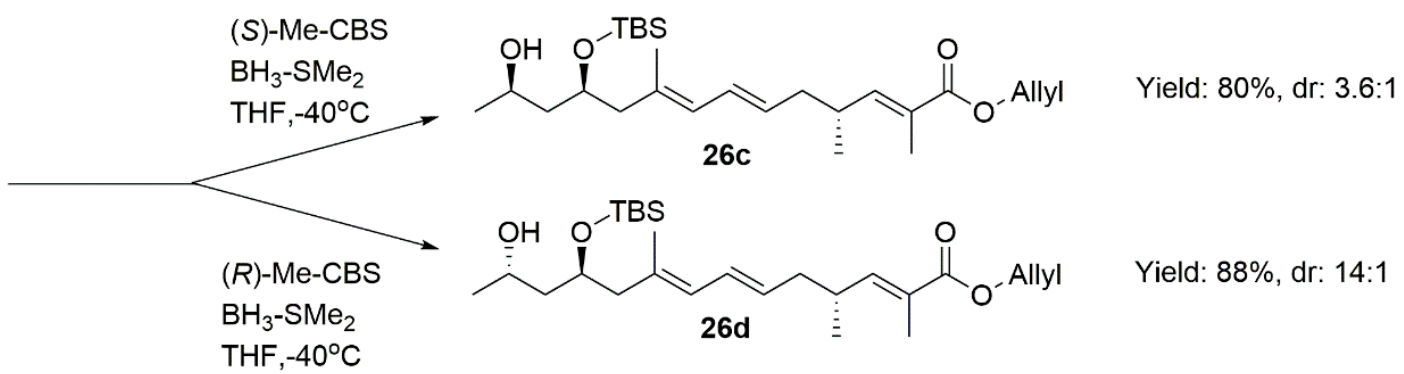

Scheme 5. Synthesis of 26a-26d.

The stereochemistries of the 1,3-diol part in 26a-26d were confirmed by their ${ }^{13} \mathrm{C}$ NMR chemical shifts of the corresponding acetonides 28a-28d (Scheme 6). Syn-diol acetonide preferred a chair conformation and two ketal methyl groups were significantly different (e.g., 19.94 and 30.46 ppm for 28a). Meanwhile anti-diol acetonide preferred a twist-boat conformation and two similar methyl groups existed (e.g., 25.24 and 25.13 ppm for 28b) [19-21].

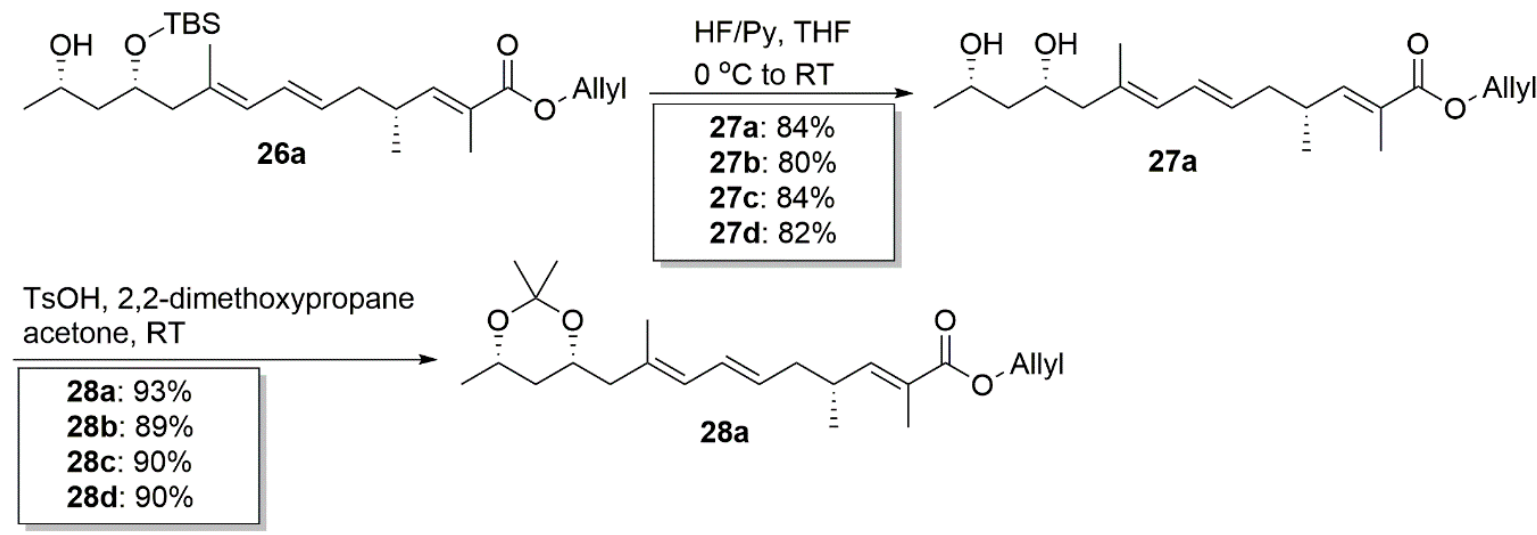<smiles>C#CC1(C)CC(C)OC(C)(C)O1</smiles>

28a<smiles>CC1CC(C)OC(C)(C)O1</smiles>

28c

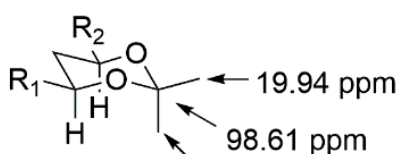
$30.46 \mathrm{ppm}$

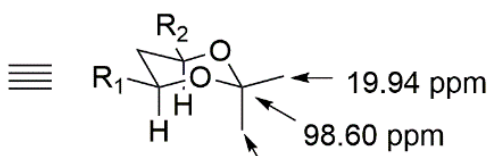
$30.45 \mathrm{ppm}$<smiles>C#CC(C)(C)[C@H]1C[C@@H](C)OC(C)(C)O1</smiles>

28b

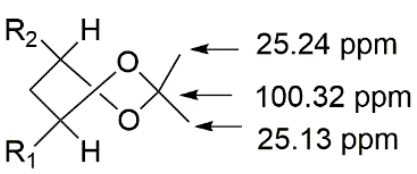

Scheme 6. Stereo-chemical assignments of 28a-28d.

After the sequential methylation and removal of the TBS group from 26a-26d, we successfully furnished the four desired analogues 1a-1d (Scheme 7). The total yield was $2.5 \%$ for $1 \mathbf{a}$ from the lactone and $2.7 \%$ for $\mathbf{1 b}, 2.5 \%$ for $1 \mathrm{c}$, and $2.6 \%$ for $\mathbf{1 d}$. 


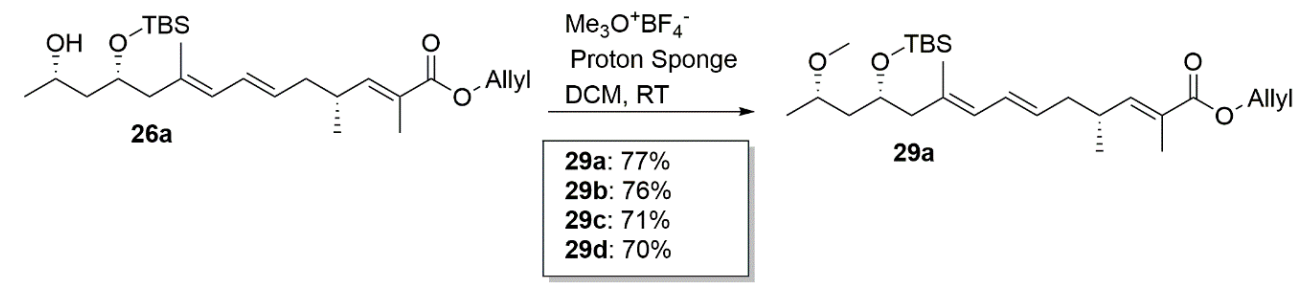

\begin{tabular}{l} 
HF/Py, THF \\
$0^{\circ} \mathrm{C}$ to RT \\
\hline 1a: $70 \%$ \\
1b: $74 \%$ \\
1c: $75 \%$ \\
1d: $74 \%$ \\
\hline
\end{tabular}

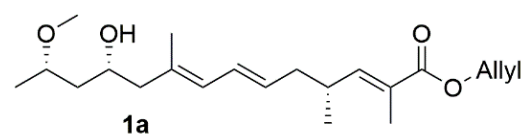

Scheme 7. Synthesis of 1a-1d.

\section{Discussion}

A careful comparison between four isomers and alotamide was conducted. The differences in ${ }^{13} \mathrm{C}$ NMR chemical shifts are shown in Figure 3a. From C15 to C28, several significant variations $(\Delta \delta>1 \mathrm{ppm})$ existed between all four isomers and alotamide possibly because of the difference between the "straight-chain" mode in our analogues and the "ring" mode in the original structure. From C28 to C32, the dihydroxy unit is a linear chain both in our analogues and natural compound. Thus, comparing the data in this portion is suitable for relative stereochemistry determination.

At the same time, several obvious variations in ${ }^{13} \mathrm{C}$ spectra were observed between 1,3 -syn isomers (1a and $\mathbf{1 c}$ ) and 1,3-anti isomers (1b and $\mathbf{1 d}$ ) from C29 to C32 (Figure 3a). Therefore, we chose $\mathbf{1 a}$ and $\mathbf{1 b}$ to represent the syn-analogues and anti-analogues to distinguish syn-configurations and anti-configurations (Figure 3b,c).

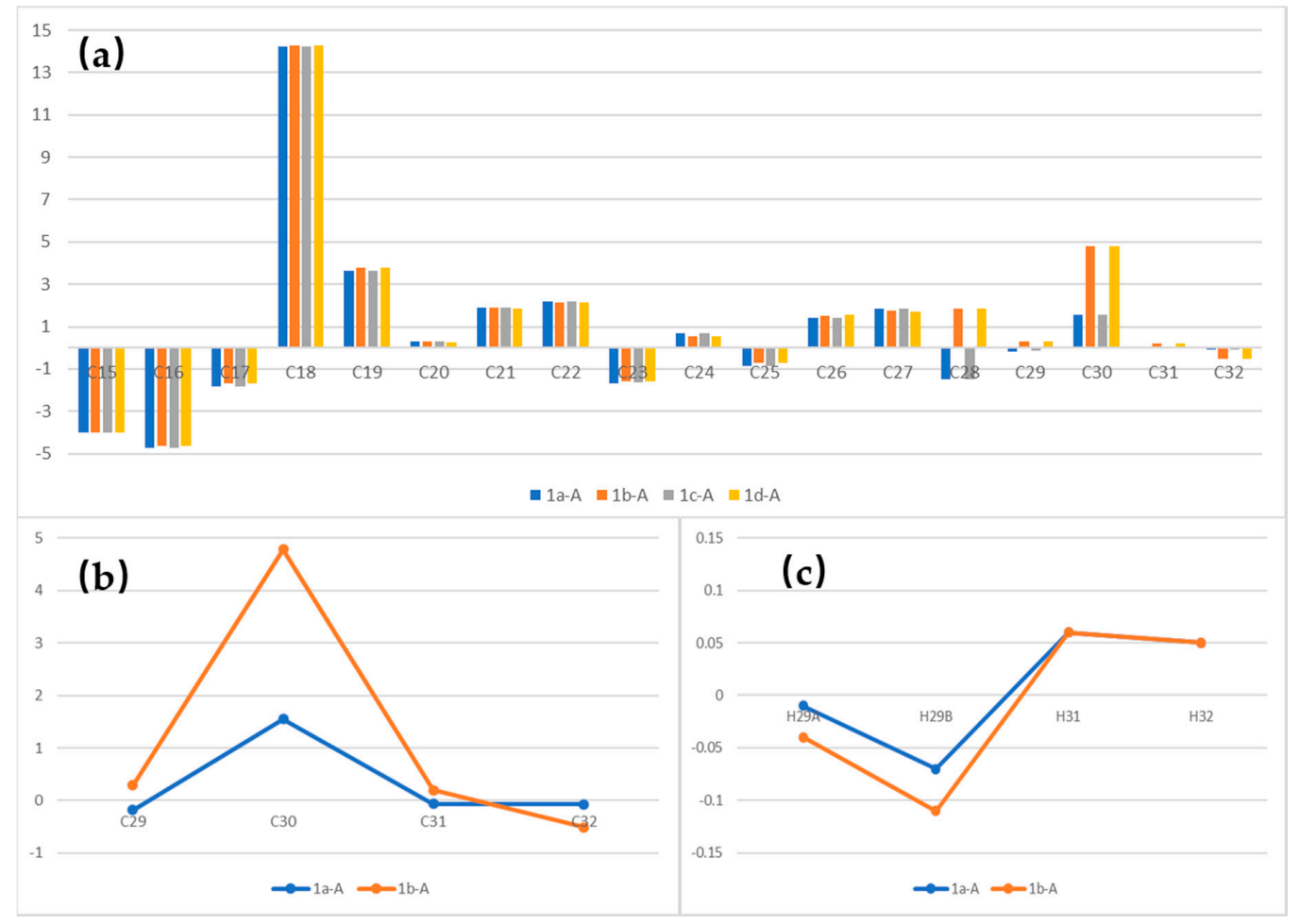

Figure 3. (a) $\Delta \delta{ }^{13} \mathrm{C}$ (ppm) between alotamide and 1a-1d, (b) $\Delta \delta{ }^{13} \mathrm{C}$ (ppm) between alotamide and 1a and $\mathbf{1 b}$ from $\mathrm{C} 29-\mathrm{C} 32,(\mathbf{c}) \Delta \delta^{1} \mathrm{H}$ (ppm) between alotamide and $\mathbf{1 a}$ and $\mathbf{1 b}$ in dihydroxy unit. 
A significant variation at $C 30$ position of $\mathbf{1 b}(\Delta \delta>4 \mathrm{ppm})$ and a closer correlation of $\mathbf{1 a}$ at $\mathrm{C} 29$, $\mathrm{C} 31$ and $\mathrm{C} 32$ in the ${ }^{13} \mathrm{C}$ spectra revealed the syn configuration in the C28-C30 unit. In addition, smaller variations with alotamide in ${ }^{1} \mathrm{H}$ spectra were noticed for analogue $1 \mathrm{a}$ at protons $\mathrm{H} 29 \mathrm{~A}$ and $\mathrm{H} 29 \mathrm{~B}$ (differences between alotamide and $\mathbf{1 a}$ and $\mathbf{1 b}$ at proton $\mathrm{H} 30$ were not plotted in Figure $3 \mathrm{c}$ because the differences were all greater than $0.4 \mathrm{ppm}$ and insignificant). This finding confirmed the 1,3-syn structure in the dihydroxy unit.

Two 1,3-syn isomers 1a and $\mathbf{1} \mathbf{c}$ were also compared. Their ${ }^{1} \mathrm{H}$ spectra were the same and the differences in ${ }^{13} \mathrm{C}$ NMR chemical shifts are listed in Table 3. A closer correlation of $1 \mathrm{c}$ was observed especially at the sites C20, C29, and C31. Thus, it appeared that 1c $(19 R, 28 S, 30 R)$ most closely fit the original natural alotamide. The total synthesis of alotamide with fragment $1 \mathrm{c}$ and another $(19 S, 28 R$, 30S) enantiomer is in progress.

Table 3. $\Delta \delta{ }^{13} \mathrm{C}(\mathrm{ppm})$ between alotamide and 1a and 1c.

\begin{tabular}{ccccccc}
\hline Isomer & C20 & C21 & C23 & C26 & C29 & C31 \\
\hline 1a & 0.30 & 1.90 & -1.67 & 1.40 & -0.18 & -0.06 \\
1c & 0.28 & 1.88 & -1.65 & 1.41 & -0.13 & -0.04 \\
\hline
\end{tabular}

\section{Materials and Methods}

All anaerobic and moisture-sensitive manipulations were carried out with standard Schlenk techniques under argon. Solvents were dried and distilled by standard procedures. ${ }^{1} \mathrm{H}$ - NMR and ${ }^{13} \mathrm{C}-\mathrm{NMR}$ spectra were recorded in $\mathrm{CDCl}_{3}$ on a Bruker Ascend- $400400 \mathrm{MHz}$ or Bruker Ascend-500 $500 \mathrm{MHz}$ at room temperature. Chemical shifts $(\delta)$ are reported in ppm and are referenced to chloroform ( $\delta 7.26 \mathrm{ppm}$ for $1 \mathrm{H}, \delta 77.16 \mathrm{ppm}$ for $\left.{ }^{13} \mathrm{C}\right)$. Data for NMR spectra are reported as follows: $\mathrm{s}=$ singlet, $\mathrm{d}=$ doublet, $\mathrm{t}=$ triplet, $\mathrm{q}=$ quartet, quint. = quintet, sext. = sextet, $\mathrm{m}=$ multiplet, $\mathrm{br}=$ broad signal, $\mathrm{J}=$ coupling constant in Hz. HRMS were recorded on an Agilent 6530-Q-TOF mass spectrometer equipped with an Agilent 1260- HPLC. Optical rotations were measured on a PerkinElmer $241 \mathrm{MC}$ polarimeter.

\section{1. (R)-3-(4-((Tert-Butyldimethylsilyl)Oxy)Butanoyl)-4-Phenyloxazolidin-2-One (7)}

To a solution of the lactone $(5 \mathrm{~g}, 58 \mathrm{mmol})$ in $\mathrm{MeOH}(50 \mathrm{~mL})$ at room temperature was added $\mathrm{LiOH}(2.44 \mathrm{~g}, 58 \mathrm{mmol})$ and stirred overnight. The solvent was removed from the reaction and the residue was dissolved in dimethylformamide $(50 \mathrm{~mL})$ at $0{ }^{\circ} \mathrm{C}$. Imidazole $(8 \mathrm{~g}, 116 \mathrm{mmol})$ was added to this solution, which was followed by TBSCl $(8.7 \mathrm{~g}, 58 \mathrm{mmol})$ in two portions over $15 \mathrm{~min}$. The reaction mixture was warmed to room temperature overnight with stirring and then diluted with $1 \mathrm{M} \mathrm{HCl}$ and extracted with EtOAc $(3 \times 100 \mathrm{~mL})$. The combined organic layers were washed with brine and dried over $\mathrm{Na}_{2} \mathrm{SO}_{4}$. The organic layer was removed under vacuum and the crude acid was used without further purification.

To a stirred solution of the acid in dry THF $(200 \mathrm{~mL})$ at $0{ }^{\circ} \mathrm{C}$ under argon, $\mathrm{Et}_{3} \mathrm{~N}(20 \mathrm{~mL}, 145 \mathrm{mmol})$ and $\mathrm{PivCl}(7.1 \mathrm{~mL}, 58 \mathrm{mmol})$ were added sequentially. After $1 \mathrm{~h}$ stirring at $0{ }^{\circ} \mathrm{C}, \mathrm{LiCl}(0.62 \mathrm{~g}, 14.5 \mathrm{mmol})$, followed by oxazolidinone $6(9.4 \mathrm{~g}, 58 \mathrm{mmol})$, were added. The reaction was continued for $1 \mathrm{~h}$ at $0{ }^{\circ} \mathrm{C}$ and another $2 \mathrm{~h}$ at room temperature prior to quenching with a saturated $\mathrm{NH}_{4} \mathrm{Cl}$ solution $(50 \mathrm{~mL})$ and extracted with DCM $(2 \times 200 \mathrm{~mL})$. The combined organic layers were washed with brine, dried over $\mathrm{Na}_{2} \mathrm{SO}_{4}$, and concentrated in vacuum. Purification by column chromatography (PE/EA = 9:1) afforded compound 7 ( $15 \mathrm{~g}, 71 \%$ for three steps) as a colorless oil.

${ }^{1} \mathrm{H}$ NMR $\left(400 \mathrm{MHz}, \mathrm{CDCl}_{3}\right) \delta 7.47-7.21(\mathrm{~m}, 5 \mathrm{H}), 5.43(\mathrm{dd}, J=8.7,3.6 \mathrm{~Hz}, 1 \mathrm{H}), 4.69(\mathrm{td}, J=8.8,1.0$ $\mathrm{Hz}, 1 \mathrm{H}), 4.28(\mathrm{ddd}, J=8.9,3.6,1.3 \mathrm{~Hz}, 1 \mathrm{H}), 3.64(\mathrm{t}, J=6.3 \mathrm{~Hz}, 2 \mathrm{H}), 3.03(\mathrm{qt}, J=17.7,7.4 \mathrm{~Hz}, 2 \mathrm{H}), 1.92-1.77$ $(\mathrm{m}, 2 \mathrm{H}), 0.90(\mathrm{~s}, 9 \mathrm{H}), 0.04(\mathrm{~d}, J=1.3 \mathrm{~Hz}, 6 \mathrm{H}) .{ }^{13} \mathrm{C}$ NMR $\left(101 \mathrm{MHz}, \mathrm{CDCl}_{3}\right) \delta 172.62,153.76,139.27$, $129.18,128.68,125.93,70.00,62.25,61.91,57.56,32.08,27.09,25.96,18.32,-5.34,-5.62 .[\alpha]_{\mathrm{D}}^{20}=-42.63$, (c 3.38, $\mathrm{CHCl}_{3}$ ). HRMS (ESI+): calcd. for $\mathrm{C}_{19} \mathrm{H}_{29} \mathrm{NO}_{4} \mathrm{~S}_{\mathrm{i}}[\mathrm{M}+\mathrm{H}]^{+}$, 364.1939; found 364.1940. 


\section{2. (R)-3-((R)-4-((Tert-Butyldimethylsilyl)oxy)-2-Methylbutanoyl)-4-Phenyloxazolidin-2-one (8)}

To a stirred solution of compound $7(15 \mathrm{~g}, 41.2 \mathrm{mmol})$ in dry THF $(100 \mathrm{~mL})$ at $-78{ }^{\circ} \mathrm{C}$ under argon, NaHMDS (2.0 M solution in THF, $24.7 \mathrm{~mL}, 49.4 \mathrm{mmol}$ ) was added dropwise. After $1 \mathrm{~h}$, MeI $(7.7 \mathrm{~mL}, 123.5 \mathrm{mmol})$ was added and the mixture was stirred overnight at the same temperature. The reaction mixture was quenched with a saturated $\mathrm{NH}_{4} \mathrm{Cl}$ solution $(100 \mathrm{~mL})$ and warmed up to room temperature before being extracted with DCM $(2 \times 100 \mathrm{~mL})$. The combined organic extracts were washed with water and brine, dried over $\mathrm{Na}_{2} \mathrm{SO}_{4}$, and concentrated in vacuum. Purification by column chromatography $(\mathrm{PE} / \mathrm{EA}=13: 1)$ gave pure $8(13.8 \mathrm{~g}, 89 \%)$ as a white solid.

${ }^{1}$ H NMR (400 MHz, $\left.\mathrm{CDCl}_{3}\right) \delta 7.45-7.23(\mathrm{~m}, 5 \mathrm{H}), 5.44(\mathrm{dd}, J=8.7,3.7 \mathrm{~Hz}, 1 \mathrm{H}), 4.67(\mathrm{t}, J=8.8 \mathrm{~Hz}$, $1 \mathrm{H}), 4.25(\mathrm{dd}, J=8.9,3.7 \mathrm{~Hz}, 1 \mathrm{H}), 4.02-3.85(\mathrm{~m}, 1 \mathrm{H}), 3.73-3.55(\mathrm{~m}, 2 \mathrm{H}), 2.00(\mathrm{td}, J=13.9,6.4 \mathrm{~Hz}, 1 \mathrm{H})$, $1.59(\mathrm{dq}, J=12.2,6.1 \mathrm{~Hz}, 1 \mathrm{H}), 1.15(\mathrm{~d}, J=7.0 \mathrm{~Hz}, 3 \mathrm{H}), 0.91(\mathrm{~s}, 9 \mathrm{H}), 0.06(\mathrm{~s}, 6 \mathrm{H}) .{ }^{13} \mathrm{C} \mathrm{NMR}(101 \mathrm{MHz}$, $\left.\mathrm{CDCl}_{3}\right) \delta 176.36,153.35,139.47,129.28,128.70,125.75,69.80,61.02,57.74,35.72,34.71,26.00,18.39,17.83$, -5.33. $[\alpha]_{\mathrm{D}}^{20}=-79.14,\left(\right.$ c 2.34, $\mathrm{CHCl}_{3}$ ). HRMS (ESI+): calcd. for $\mathrm{C}_{20} \mathrm{H}_{31} \mathrm{NO}_{4} \mathrm{~S}_{\mathrm{i}}[\mathrm{M}+\mathrm{H}]^{+}, 378.2095$, found 378.2095 .

\section{3. (R)-4-((Tert-Butyldimethylsilyl)Oxy)-2-Methylbutan-1-Ol (9)}

To an ice-cold solution of compound $8(13.8 \mathrm{~g}, 36.6 \mathrm{mmol})$ in THF $(100 \mathrm{~mL})$ moist with a catalytic amount of water, $\mathrm{LiBH}_{4}(1.2 \mathrm{~g}, 54.9 \mathrm{mmol})$ was added portion wise under argon. After $12 \mathrm{~h}$ of stirring at room temperature, the reaction was quenched cautiously with a saturated $\mathrm{NH}_{4} \mathrm{Cl}$ solution (50 mL) and then distilled under a reduced pressure followed by extraction with DCM. The combined organic solution was dried over $\mathrm{Na}_{2} \mathrm{SO}_{4}$ and concentrated in vacuum. Purification by column chromatography $(\mathrm{PE} / \mathrm{EA}=9: 1)$ provided pure compound $9(6.86 \mathrm{~g}, 86 \%)$ as a colorless oil [11].

${ }^{1}$ H NMR (400 MHz, CDCl $)$ א 3.81-3.69 (m, 1H), 3.68-3.60 (m, 1H), $3.46(\mathrm{~s}, 1 \mathrm{H}), 3.43-3.33(\mathrm{~m}, 1 \mathrm{H})$, $3.19(\mathrm{~s}, 1 \mathrm{H}), 1.86-1.70(\mathrm{~m}, 1 \mathrm{H}), 1.59-1.46(\mathrm{~m}, 2 \mathrm{H}), 0.89(\mathrm{~m}, 12 \mathrm{H}), 0.05(\mathrm{~s}, 6 \mathrm{H}) .{ }^{13} \mathrm{C} \mathrm{NMR}(101 \mathrm{MHz}$, $\left.\mathrm{CDCl}_{3}\right) \delta 68.21,61.82,37.53,34.46,25.98,18.34,17.46,-5.33,-5.36 .[\alpha]_{\mathrm{D}}^{20}=-10.98,\left(c 1.82, \mathrm{CHCl}_{3}\right)$. HRMS (ESI+): calcd. for $\mathrm{C}_{11} \mathrm{H}_{26} \mathrm{O}_{2} \mathrm{~S}_{\mathrm{i}}[\mathrm{M}+\mathrm{H}]^{+}, 219.1775$, found 219.1771 .

\subsection{Ethyl (R,E)-6-((Tert-Butyldimethylsilyl)Oxy)-2,4-Dimethylhex-2-Enoate (11)}

To a stirred solution of $9(6.86 \mathrm{~g}, 31.5 \mathrm{mmol})$ in DMSO $(50 \mathrm{~mL}) \mathrm{IBX}(10.6 \mathrm{~g}, 37.8 \mathrm{mmol})$ was added. After $1 \mathrm{~h}$ stirring at $40{ }^{\circ} \mathrm{C}$, the reaction was quenched with water $(50 \mathrm{~mL})$ and extracted with ether $(2 \times 100 \mathrm{~mL})$. The combined organic layers were washed with brine, dried over $\mathrm{Na}_{2} \mathrm{SO}_{4}$, and removed under vacuum. The residue was refluxed with $10(22 \mathrm{~g}, 63 \mathrm{mmol})$ in toluene $(100 \mathrm{~mL})$ at $80{ }^{\circ} \mathrm{C}$ for $3 \mathrm{~h}$ and the solvent was removed under vacuum. Purification by column chromatography $(\mathrm{PE} / \mathrm{EA}=40: 1)$ provided pure compound $\mathbf{1 1}(7 \mathrm{~g}, 75 \%)$ as a colorless oil [22].

${ }^{1} \mathrm{H}$ NMR $\left(400 \mathrm{MHz}, \mathrm{CDCl}_{3}\right) \delta 6.53(\mathrm{dd}, J=10.1,1.4 \mathrm{~Hz}, 1 \mathrm{H}), 4.17(\mathrm{q}, J=7.1 \mathrm{~Hz}, 2 \mathrm{H}), 3.70-3.41$ (m, 2H), 2.80-2.45 (m, 1H), $1.83(\mathrm{~d}, J=1.4 \mathrm{~Hz}, 3 \mathrm{H}), 1.66-1.44(\mathrm{~m}, 2 \mathrm{H}), 1.28(\mathrm{t}, J=7.1 \mathrm{~Hz}, 3 \mathrm{H})$, $1.00(\mathrm{~d}, J=6.7 \mathrm{~Hz}, 3 \mathrm{H}), 0.87(\mathrm{~s}, 9 \mathrm{H}), 0.01(\mathrm{~d}, J=2.1 \mathrm{~Hz}, 6 \mathrm{H}) .{ }^{13} \mathrm{C} \mathrm{NMR}\left(101 \mathrm{MHz}, \mathrm{CDCl}_{3}\right) \delta 168.57$, $147.56,126.83,61.02,60.52,39.83,29.78,26.04,20.06,18.37,14.42,12.59,-5.23,-5.25 .[\alpha]_{\mathrm{D}}^{20}=-2.167$, (c $0.1, \mathrm{CHCl}_{3}$ ). HRMS (ESI+): calcd. for $\mathrm{C}_{16} \mathrm{H}_{32} \mathrm{O}_{3} \mathrm{~S}_{\mathrm{i}}[\mathrm{M}+\mathrm{H}]^{+}, 301.2193$, found 301.2194.

\subsection{Allyl (R,E)-6-((Tert-Butyldimethylsilyl)oxy)-2,4-Dimethylhex-2-Enoate (12)}

To a stirred solution of compound $11(7 \mathrm{~g}, 23.6 \mathrm{mmol})$ in dry DCM $(60 \mathrm{~mL})$ at $-78{ }^{\circ} \mathrm{C}$ under argon, DIBAL-H (1.5 M solution in toluene, $18.0 \mathrm{~mL}, 27.0 \mathrm{mmol}$ ) was added dropwise. After $1 \mathrm{~h}$, the reaction mixture was quenched with aqueous sodium-potassium tartrate solution $(20 \mathrm{~mL})$ and warmed up to room temperature before being extracted with DCM $(2 \times 100 \mathrm{~mL})$. The combined organic extracts were washed with water and brine, dried over $\mathrm{Na}_{2} \mathrm{SO}_{4}$, and concentrated in vacuum. Purification by column chromatography $(\mathrm{PE} / \mathrm{EA}=8: 1)$ gave alcohol $(4.8 \mathrm{~g}, 79 \%)$ as a colorless oil. 
To a stirred solution of above alcohol in DMSO (50 mL), IBX (6.2 g, $22 \mathrm{mmol})$ was added. After $1 \mathrm{~h}$ stirring at $40^{\circ} \mathrm{C}$, the reaction was quenched with water $(50 \mathrm{~mL})$ and extracted with ether $(2 \times 100 \mathrm{~mL})$. The combined organic layers were washed with brine, dried over $\mathrm{Na}_{2} \mathrm{SO}_{4}$, and removed under vacuum. The crude anhydride was used without further purification.

To the solution of above crude aldehyde in ${ }^{\mathrm{t}} \mathrm{BuOH}(40 \mathrm{~mL}), \mathrm{NaH}_{2} \mathrm{PO}_{4}(11 \mathrm{~g}, 93 \mathrm{mmol})$ in $\mathrm{H}_{2} \mathrm{O}$ (40 mL), 2-methyl-2-butene (19 mL, $186 \mathrm{mmol})$, and $\mathrm{NaClO}_{2}(3.1 \mathrm{~g}, 28 \mathrm{mmol},>79.0 \%$ purity) were added. After stirring for $2 \mathrm{~h}$ at room temperature, the mixture was extracted with EA $(50 \mathrm{~mL} \times 3)$ and the combined organic layers were washed with brine, dried over $\mathrm{Na}_{2} \mathrm{SO}_{4}$, filtrated, and concentrated. The crude acid was taken into the next step without future purification.

To a stirred solution of above acid in dry DMF $(50 \mathrm{~mL})$ allylBr $(3.2 \mathrm{~g}, 37.2 \mathrm{mmol})$ and $\mathrm{K}_{2} \mathrm{CO}_{3}$ ( $5.1 \mathrm{~g}, 37.2 \mathrm{mmol}$ ) were added separately. After being stirred for $12 \mathrm{~h}$, the mixture was quenched with a saturated aqueous solution of $\mathrm{NH}_{4} \mathrm{Cl}$ and extracted with $\mathrm{EA}(100 \mathrm{~mL} \times 3)$. The combined organic layers were washed with brine, dried over $\mathrm{Na}_{2} \mathrm{SO}_{4}$, filtrated, and concentrated. The residue was purified by column chromatography on silica gel (PE/EA $=40: 1)$ to give $\mathbf{1 2}(4.7 \mathrm{~g}, 81 \%)$ for three steps as a colorless oil.

${ }^{1} \mathrm{H}$ NMR $\left(400 \mathrm{MHz}, \mathrm{CDCl}_{3}\right) \delta 6.58(\mathrm{dd}, J=10.1,1.4 \mathrm{~Hz}, 1 \mathrm{H}), 5.96(\mathrm{ddt}, J=17.1,10.5,5.6 \mathrm{~Hz}$, $1 \mathrm{H}), 5.32(\mathrm{ddd}, J=17.2,3.0,1.5 \mathrm{~Hz}, 1 \mathrm{H}), 5.23(\mathrm{dd}, J=10.4,1.3 \mathrm{~Hz}, 1 \mathrm{H}), 4.64(\mathrm{dt}, J=5.6,1.4 \mathrm{~Hz}, 2 \mathrm{H})$, 3.66-3.42 (m, 2H), 2.82-2.58 (m, 1H), $1.86(\mathrm{~d}, J=1.4 \mathrm{~Hz}, 3 \mathrm{H}), 1.68-1.55(\mathrm{~m}, 2 \mathrm{H}), 1.01(\mathrm{~d}, J=6.7 \mathrm{~Hz}$, $3 \mathrm{H}), 0.88(\mathrm{~s}, 10 \mathrm{H}), 0.02(\mathrm{~d}, J=2.2 \mathrm{~Hz}, 6 \mathrm{H}) .{ }^{13} \mathrm{C}$ NMR $\left(101 \mathrm{MHz}, \mathrm{CDCl}_{3}\right) \delta 168.16,148.14,132.76,126.60$, $117.84,65.27,61.00,39.80,29.82,26.04,20.02,18.38,12.62,-5.22 .[\alpha]_{\mathrm{D}}^{20}=-53.365,\left(c 0.52, \mathrm{CHCl}_{3}\right)$. HRMS (ESI+): calcd. for $\mathrm{C}_{17} \mathrm{H}_{32} \mathrm{O}_{3} \mathrm{~S}_{\mathrm{i}}[\mathrm{M}+\mathrm{H}]^{+}, 313.2193$, found 313.2186.

\subsection{Allyl (R,E)-6-Hydroxy-2,4-Dimethylhex-2-Enoate (13)}

To a stirred solution of $12(4.7 \mathrm{~g}, 15 \mathrm{mmol})$ in dry THF $(10 \mathrm{~mL})$, the HF/Py complex $(2 \mathrm{~mL})$ was added at $0{ }^{\circ} \mathrm{C}$. After being stirred for $1 \mathrm{~h}$, the mixture was quenched with a saturated aqueous solution of $\mathrm{NaHCO}_{3}$ and extracted with $\mathrm{DCM}(20 \mathrm{~mL} \times 3)$. The combined organic layers were washed with $1 \mathrm{M} \mathrm{HCl}$ brine, dried over $\mathrm{Na}_{2} \mathrm{SO}_{4}$, filtrated, and concentrated. The residue was purified by column chromatography on silica gel (PE/EA $=6: 1)$ to give $\mathbf{1 3}(2.3 \mathrm{~g}, 77 \%)$ as a colorless oil.

${ }^{1} \mathrm{H}$ NMR $\left(400 \mathrm{MHz}, \mathrm{CDCl}_{3}\right) \delta 6.59(\mathrm{dd}, J=10.1,1.4 \mathrm{~Hz}, 1 \mathrm{H}), 5.97(\mathrm{ddt}, J=17.1,10.6,5.6 \mathrm{~Hz}, 1 \mathrm{H})$, $5.34(\mathrm{dq}, J=17.2,1.5 \mathrm{~Hz}, 1 \mathrm{H}), 5.24(\mathrm{ddd}, J=10.5,2.6,1.3 \mathrm{~Hz}, 1 \mathrm{H}), 4.65(\mathrm{dt}, J=5.6,1.4 \mathrm{~Hz}, 2 \mathrm{H}), 3.75-3.44$ $(\mathrm{m}, 2 \mathrm{H}), 2.78-2.63(\mathrm{~m}, 1 \mathrm{H}), 1.88(\mathrm{~d}, J=1.4 \mathrm{~Hz}, 3 \mathrm{H}), 1.75-1.62(\mathrm{~m}, 1 \mathrm{H}), 1.62-1.50(\mathrm{~m}, 2 \mathrm{H}), 1.05(\mathrm{~d}, J=6.7$ $\mathrm{Hz}, 3 \mathrm{H}) .{ }^{13} \mathrm{C}$ NMR $\left(101 \mathrm{MHz}, \mathrm{CDCl}_{3}\right) \delta 168.07,147.61,132.63,126.88,117.97,65.34,60.94,39.55,29.97$, 20.09, 12.62. $[\alpha]_{\mathrm{D}}^{20}=-55.72,\left(c 0.79, \mathrm{CHCl}_{3}\right)$. HRMS (ESI+): calcd. for $\mathrm{C}_{11} \mathrm{H}_{18} \mathrm{O}_{3}[\mathrm{M}+\mathrm{H}]^{+}, 199.1329$, found 199.1328.

\subsection{Allyl (R,E)-2,4-Dimethyl-6-((1-Phenyl-1H-Tetrazol-5-yl)Thio)Hex-2-Enoate (15)}

To a stirred solution of $\mathbf{1 3}(2.3 \mathrm{~g}, 11.6 \mathrm{mmol})$ in anhydrous dry THF $(50 \mathrm{~mL})$ at $0{ }^{\circ} \mathrm{C}$ under argon, $\mathrm{PPh}_{3}(6.1 \mathrm{~g}, 23.2 \mathrm{mmol}), 14(2 \mathrm{~g}, 11.6 \mathrm{mmol})$, and DIAD $(4.6 \mathrm{~mL}, 23.2 \mathrm{mmol})$ were added sequentially. The reaction was continued further for $1 \mathrm{~h}$ at room temperature prior to quenching with the saturated $\mathrm{NH}_{4} \mathrm{Cl}$ solution $(50 \mathrm{~mL})$ and extracted with $\mathrm{DCM}(2 \times 100 \mathrm{~mL})$. The combined organic layers were washed with brine, dried over $\mathrm{Na}_{2} \mathrm{SO}_{4}$, and concentrated in vacuum. Purification by column chromatography (PE/EA $=15: 1)$ afforded compound $15(3.9 \mathrm{~g}, 94 \%)$ as a colorless oil.

${ }^{1} \mathrm{H}$ NMR $\left(400 \mathrm{MHz}, \mathrm{CDCl}_{3}\right) \delta 7.67-7.46(\mathrm{~m}, 5 \mathrm{H}), 6.55(\mathrm{dd}, J=10.1,1.4 \mathrm{~Hz}, 1 \mathrm{H}), 5.94(\mathrm{ddt}, J=17.1$, $10.5,5.6 \mathrm{~Hz}, 1 \mathrm{H}), 5.42-5.29(\mathrm{~m}, 1 \mathrm{H}), 5.22(\mathrm{dd}, J=10.4,1.3 \mathrm{~Hz}, 1 \mathrm{H}), 4.62(\mathrm{dt}, J=5.6,1.4 \mathrm{~Hz}, 2 \mathrm{H}), 3.41-3.13$ $(\mathrm{m}, 2 \mathrm{H}), 2.77-2.60(\mathrm{~m}, 1 \mathrm{H}), 2.06-1.90(\mathrm{~m}, 1 \mathrm{H}), 1.89-1.74(\mathrm{~m}, 4 \mathrm{H}), 1.05(\mathrm{~d}, J=6.7 \mathrm{~Hz}, 3 \mathrm{H}) .{ }^{13} \mathrm{C}$ NMR $\left(101 \mathrm{MHz}, \mathrm{CDCl}_{3}\right) \delta 167.69,154.18,146.10,133.74,132.49,130.22,129.89,127.82,123.90,118.07,65.40$, $35.95,32.63,31.37,19.89,12.76 .[\alpha]_{D}^{20}=-58.87,\left(c 1.47, \mathrm{CHCl}_{3}\right)$. HRMS (ESI+): calcd. for $\mathrm{C}_{18} \mathrm{H}_{22} \mathrm{~N}_{4} \mathrm{O}_{2} \mathrm{~S}$ $[\mathrm{M}+\mathrm{H}]^{+}, 359.1536$, found 359.1532 . 


\subsection{Allyl (R,E)-2,4-Dimethyl-6-((1-Phenyl-1H-Tetrazol-5-yl)sulfonyl)Hex-2-Enoate (2)}

To a stirred solution of $\mathbf{1 5}(3.9 \mathrm{~g}, 10.1 \mathrm{mmol})$ in ethanol $(100 \mathrm{~mL})$ at $0{ }^{\circ} \mathrm{C},\left(\mathrm{NH}_{4}\right)_{6} \mathrm{Mo}_{7} \mathrm{O}_{24}(2.9 \mathrm{~g}$, $2.2 \mathrm{mmol})$ and $\mathrm{H}_{2} \mathrm{O}_{2}(20 \mathrm{~mL})$ were added sequentially. The reaction was continued further for $12 \mathrm{~h}$ at room temperature prior to quenching with saturated $\mathrm{NH}_{4} \mathrm{Cl}$ solution $(50 \mathrm{~mL})$ and extracted with $\operatorname{DCM}(2 \times 100 \mathrm{~mL})$. The combined organic layers were washed with brine, dried over $\mathrm{Na}_{2} \mathrm{SO}_{4}$, and concentrated in vacuum. Purification by column chromatography $(\mathrm{PE} / \mathrm{EA}=8: 1)$ afforded compound $2(3.6 \mathrm{~g}, 94 \%)$ as a white solid.

${ }^{1} \mathbf{H}$ NMR $\left(400 \mathrm{MHz}, \mathrm{CDCl}_{3}\right) \delta 7.76-7.51(\mathrm{~m}, 5 \mathrm{H}), 6.53(\mathrm{dd}, J=10.1,1.4 \mathrm{~Hz}, 1 \mathrm{H}), 5.97(\mathrm{ddt}, J=17.1$, $10.5,5.6 \mathrm{~Hz}, 1 \mathrm{H}), 5.48-5.32(\mathrm{~m}, 1 \mathrm{H}), 5.25(\mathrm{dd}, J=10.4,1.3 \mathrm{~Hz}, 1 \mathrm{H}), 4.65(\mathrm{dt}, J=5.6,1.3 \mathrm{~Hz}, 2 \mathrm{H}), 3.77-3.58$ $(\mathrm{m}, 2 \mathrm{H}), 2.95-2.62(\mathrm{~m}, 1 \mathrm{H}), 2.24-2.04(\mathrm{~m}, 1 \mathrm{H}), 2.01-1.92(\mathrm{~m}, 1 \mathrm{H}), 1.88(\mathrm{~d}, J=1.4 \mathrm{~Hz}, 3 \mathrm{H}), 1.11(\mathrm{~d}, J=6.7$ $\mathrm{Hz}, 3 \mathrm{H}) .{ }^{13} \mathrm{C}$ NMR $\left(101 \mathrm{MHz}, \mathrm{CDCl}_{3}\right) \delta 167.47,153.49,144.44,133.12,132.42,131.64,129.88,128.93$, $125.17,118.32,65.61,54.40,32.31,28.74,19.98,12.86 .[\alpha]_{\mathrm{D}}^{20}=-13.87,\left(c 0.79, \mathrm{CHCl}_{3}\right)$. HRMS (ESI+): calcd. for $\mathrm{C}_{18} \mathrm{H}_{22} \mathrm{~N}_{4} \mathrm{O}_{2} \mathrm{~S}_{2}[\mathrm{M}+\mathrm{H}]^{+}, 391.1435$, found 391.1435.

\subsection{4-((4-Methoxybenzyl)Oxy)Butan-2-One (16)}

To a stirred solution of 4-hydroxy-2-butanone $(1.1 \mathrm{~mL}, 12.8 \mathrm{mmol})$ in dry THF $(20 \mathrm{~mL})$ at $0{ }^{\circ} \mathrm{C}$, 4-methoxybenzyl 2,2,2-trichloroacetimidate $(2 \mathrm{~mL}, 10.7 \mathrm{mmol})$ and triphenylcarbenium tetrafluoroborate (cat.) were added sequentially. The reaction was continued further for $1 \mathrm{~h}$ at room temperature prior to quenching with the saturated $\mathrm{NH}_{4} \mathrm{Cl}$ solution $(50 \mathrm{~mL})$ and extracted with DCM $(2 \times 100 \mathrm{~mL})$. The combined organic layers were washed with brine, dried over $\mathrm{Na}_{2} \mathrm{SO}_{4}$, and concentrated in vacuum. Purification by column chromatography (PE/EA $=6: 1$ ) afforded compound $16(1.8 \mathrm{~g}, 82 \%)$ as a colorless oil [14].

${ }^{1} \mathrm{H}$ NMR $\left(400 \mathrm{MHz}, \mathrm{CDCl}_{3}\right) \delta$ 7.33-7.18 (m, 2H), 6.94-6.81 (m, 2H), $4.45(\mathrm{~s}, 2 \mathrm{H}), 3.81(\mathrm{~s}, 3 \mathrm{H}), 3.72$ $(\mathrm{t}, J=6.3 \mathrm{~Hz}, 2 \mathrm{H}), 2.71(\mathrm{t}, J=6.3 \mathrm{~Hz}, 2 \mathrm{H}), 2.18(\mathrm{~s}, 3 \mathrm{H}) .{ }^{13} \mathrm{C} \mathrm{NMR}\left(101 \mathrm{MHz}, \mathrm{CDCl}_{3}\right) \delta 207.51,159.27$, $130.16,129.42,113.84,72.91,64.96,55.31,43.81,30.48$. HRMS (ESI+): calcd. for $\mathrm{C}_{12} \mathrm{H}_{16} \mathrm{O}_{3}[\mathrm{M}+\mathrm{H}]^{+}$, 209.1172, found 209.1170.

\subsection{Ethyl (E)-5-((4-Methoxybenzyl)Oxy)-3-Methylpent-2-Enoate (17)}

To a stirred solution of triethyl phosphonoacetate $(3.5 \mathrm{~mL}, 17.5 \mathrm{mmol})$ in dry THF $(50 \mathrm{~mL})$ at $0{ }^{\circ} \mathrm{C}$, $\mathrm{NaH}(0.7 \mathrm{~g}, 17.5 \mathrm{mmol})$ was added. After stirring at room temperature for $1 \mathrm{~h}, \mathbf{1 6}(1.8 \mathrm{~g}, 8.8 \mathrm{mmol})$ in THF $(5 \mathrm{~mL})$ was added at $0{ }^{\circ} \mathrm{C}$. The reaction was continued further for $12 \mathrm{~h}$ at room temperature prior to quenching with a saturated $\mathrm{NH}_{4} \mathrm{Cl}$ solution $(50 \mathrm{~mL})$ and extracted with $\mathrm{DCM}(2 \times 100 \mathrm{~mL})$. The combined organic layers were washed with brine, dried over $\mathrm{Na}_{2} \mathrm{SO}_{4}$, and concentrated in vacuum. Purification by column chromatography (PE/EA = 20:1) afforded compound $\mathbf{1 7}$ in the $E / Z$ mixture $(1.7 \mathrm{~g}, 70 \%)$ as a colorless oil.

${ }^{1} \mathbf{H}$ NMR $\left(400 \mathrm{MHz}, \mathrm{CDCl}_{3}\right) \delta 7.27(\mathrm{~d}, J=8.6 \mathrm{~Hz}, 2 \mathrm{H}), 6.99-6.72(\mathrm{~m}, 2 \mathrm{H}), 5.82-5.63(\mathrm{~m}, 1 \mathrm{H}), 4.47$ $(\mathrm{d}, J=2.8 \mathrm{~Hz}, 2 \mathrm{H}), 4.23-4.08(\mathrm{~m}, 2 \mathrm{H}), 3.82(\mathrm{~d}, J=2.1 \mathrm{~Hz}, 3 \mathrm{H}), 3.70-3.51(\mathrm{~m}, 2 \mathrm{H}), 2.98(\mathrm{t}, J=6.6 \mathrm{~Hz}$, $1 \mathrm{H}), 2.45(\mathrm{t}, J=6.4 \mathrm{~Hz}, 2 \mathrm{H}), 2.19(\mathrm{~d}, J=1.2 \mathrm{~Hz}, 2 \mathrm{H}), 1.96(\mathrm{~d}, J=1.3 \mathrm{~Hz}, 1 \mathrm{H}), 1.29(\mathrm{td}, J=7.1,5.4 \mathrm{~Hz}$, 3H). ${ }^{13}$ C NMR $\left(101 \mathrm{MHz}, \mathrm{CDCl}_{3}\right) \delta 166.73,166.34,159.33,159.19,157.81,156.72,130.70,130.30,129.38$, 129.27, 117.46, 117.10, 113.90, 113.81, 72.76, 72.46, 68.74, 67.59, 59.60, 55.35, 40.89, 33.73, 26.16, 19.00, 14.42. HRMS (ESI+): calcd. for $\mathrm{C}_{16} \mathrm{H}_{22} \mathrm{O}_{4}[\mathrm{M}+\mathrm{H}]^{+}, 279.1591$; found 279.1589 .

\subsection{Ethyl (E)-5-Hydroxy-3-Methylpent-2-Enoate (18)}

To a stirring solution of $\mathbf{1 7}(1.7 \mathrm{~g}, 6.1 \mathrm{mmol})$ in DCM $(20 \mathrm{~mL})$ and water $(4 \mathrm{~mL}) \mathrm{DDQ}(1.67 \mathrm{~g}$, $7.3 \mathrm{mmol}$ ) was added at room temperature. After $1 \mathrm{~h}$, the reaction mixture was quenched with saturated aqueous $\mathrm{NaHCO}_{3}(10 \mathrm{~mL})$ and $1 \mathrm{M}$ aqueous $\mathrm{NaHSO}_{3}(10 \mathrm{~mL})$ and extracted with DCM $(30 \mathrm{~mL} \times 3)$. The combined organic layers were washed with brine, dried over $\mathrm{Na}_{2} \mathrm{SO}_{4}$, and concentrated. The crude product was purified by column chromatography $(\mathrm{PE} / \mathrm{EA}=3: 1)$ to give the desired compound 18 as a colorless oil (672 $\mathrm{mg}, 70 \%$ yield) [13]. 
${ }^{1} \mathrm{H}$ NMR $\left(400 \mathrm{MHz}, \mathrm{CDCl}_{3}\right) \delta 5.71(\mathrm{~d}, J=1.2 \mathrm{~Hz}, 1 \mathrm{H}), 4.12(\mathrm{q}, J=7.1 \mathrm{~Hz}, 2 \mathrm{H}), 3.76(\mathrm{t}, J=6.4 \mathrm{~Hz}$, 2H), 2.47-2.30 (m, 2H), $2.16(\mathrm{~d}, J=1.2 \mathrm{~Hz}, 3 \mathrm{H}), 1.92(\mathrm{~s}, 1 \mathrm{H}), 1.25(\mathrm{t}, J=7.1 \mathrm{~Hz}, 3 \mathrm{H}) .{ }^{13} \mathrm{C}$ NMR $(101 \mathrm{MHz}$, $\left.\mathrm{CDCl}_{3}\right) \delta 166.67,156.12,117.73,60.22,59.78,43.82,18.82,14.37$. HRMS (ESI+): calcd. for $\mathrm{C}_{8} \mathrm{H}_{14} \mathrm{O}_{3}$ $[\mathrm{M}+\mathrm{H}]^{+}, 159.1016$, found 159.1014.

\subsection{Ethyl (E)-5-((Tert-Butyldimethylsilyl)Oxy)-3-Methylpent-2-Enoate (19)}

To a stirred solution of $\mathbf{1 8}(672 \mathrm{mg}, 4.3 \mathrm{mmol})$ in anhydrous DMF $(10 \mathrm{~mL})$ at $0{ }^{\circ} \mathrm{C}$, imidazole $(7.7 \mathrm{~g}, 11.4 \mathrm{mmol})$ and $\mathrm{TBSCl}(1.1 \mathrm{~g}, 6.84 \mathrm{mmol})$ were added sequentially. The reaction was continued further for $12 \mathrm{~h}$ at room temperature prior to quenching with saturated $\mathrm{NH}_{4} \mathrm{Cl}$ solution $(20 \mathrm{~mL})$ and extracted with EA $(2 \times 20 \mathrm{~mL})$. The combined organic layers were washed with brine, dried over $\mathrm{Na}_{2} \mathrm{SO}_{4}$, and concentrated in vacuum. Purification by column chromatography (PE/EA = 40:1) created compound $19(1.05 \mathrm{~g}, 90 \%)$ as a colorless oil [13].

${ }^{1} \mathrm{H}$ NMR $\left(400 \mathrm{MHz}, \mathrm{CDCl}_{3}\right) \delta 5.66(\mathrm{~d}, J=1.1 \mathrm{~Hz}, 1 \mathrm{H}), 4.12(\mathrm{q}, J=7.1 \mathrm{~Hz}, 2 \mathrm{H}), 2.32(\mathrm{t}, J=6.6 \mathrm{~Hz}$, 2H), $2.15(\mathrm{~d}, J=1.2 \mathrm{~Hz}, 3 \mathrm{H}), 1.24(\mathrm{t}, J=7.1 \mathrm{~Hz}, 3 \mathrm{H}), 0.86(\mathrm{~s}, 9 \mathrm{H}), 0.02(\mathrm{~s}, 6 \mathrm{H}) .{ }^{13} \mathrm{C}$ NMR $(101 \mathrm{MHz}$, $\left.\mathrm{CDCl}_{3}\right) \delta 166.74,156.92,117.34,61.41,59.53,44.12,25.97,19.21,18.36,14.42,-5.29$. HRMS (ESI+): calcd. for $\mathrm{C}_{14} \mathrm{H}_{28} \mathrm{O}_{3} \mathrm{Si}[\mathrm{M}+\mathrm{H}]^{+}$, 273.1880, found 273.1880.

\subsection{3. (E)-5-((Tert-Butyldimethylsilyl)Oxy)-3-Methylpent-2-En-1-Ol (20)}

To a stirred solution of compound $19(1.05 \mathrm{~g}, 3.87 \mathrm{mmol})$ in dry DCM $(15 \mathrm{~mL})$ at $-78{ }^{\circ} \mathrm{C}$ under argon, DIBAL-H (1.5 M solution in toluene, $3.9 \mathrm{~mL}, 5.8 \mathrm{mmol})$ was added dropwise. After $1 \mathrm{~h}$, the reaction mixture was quenched with the aqueous sodium-potassium tartrate solution $(20 \mathrm{~mL})$ and warmed up to room temperature before being extracted with DCM $(2 \times 20 \mathrm{~mL})$. The combined organic extracts were washed with water and brine, dried over $\mathrm{Na}_{2} \mathrm{SO}_{4}$, and concentrated in vacuum. Purification by column chromatography (PE/EA $=7: 1)$ gave $20(680 \mathrm{mg}, 76 \%)$ as a colorless oil [23].

${ }^{1} \mathrm{H}$ NMR $\left(400 \mathrm{MHz}, \mathrm{CDCl}_{3}\right) \delta 5.45(\mathrm{td}, J=6.9,1.2 \mathrm{~Hz}, 1 \mathrm{H}), 4.16(\mathrm{~d}, J=6.9 \mathrm{~Hz}, 2 \mathrm{H}), 3.71(\mathrm{t}, J=7.0 \mathrm{~Hz}$, 2H), $2.25(\mathrm{t}, J=7.0 \mathrm{~Hz}, 2 \mathrm{H}), 1.71(\mathrm{~s}, 3 \mathrm{H}), 1.53(\mathrm{~s}, 1 \mathrm{H}), 0.90(\mathrm{~s}, 9 \mathrm{H}), 0.06(\mathrm{~s}, 6 \mathrm{H}) .{ }^{13} \mathrm{C}$ NMR $(101 \mathrm{MHz}$, $\left.\mathrm{CDCl}_{3}\right) \delta 136.95,125.38,62.20,59.42,42.91,26.05,18.45,16.80,-5.17$. HRMS (ESI+): calcd. for $\mathrm{C}_{12} \mathrm{H}_{26} \mathrm{O}_{2} \mathrm{Si}\left([\mathrm{M}+\mathrm{H}]^{+}, 231.1775\right.$, found 231.1775.

\subsection{Allyl (R,2E,6E,8E)-11-((Tert-butyldimethylsilyl)Oxy)-2,4,9-Trimethylundeca-2,6,8-Trienoate (21a)}

To a stirred solution of $20(680 \mathrm{mg}, 3.0 \mathrm{mmol})$ in DMSO $(10 \mathrm{~mL}) \mathrm{IBX}(990 \mathrm{mg}, 3.5 \mathrm{mmol})$ was added. After $1 \mathrm{~h}$ of stirring at $40{ }^{\circ} \mathrm{C}$, the reaction was quenched with water $(10 \mathrm{~mL})$ and extracted with ether $(2 \times 20 \mathrm{~mL})$. The combined organic layers were washed with brine, dried over $\mathrm{Na}_{2} \mathrm{SO}_{4}$, and removed under vacuum. The crude aldehyde 3 was used without further purification.

To a stirred solution of crude 3 and compound $2(1.3 \mathrm{~g}, 3.3 \mathrm{mmol})$ in dry THF $(30 \mathrm{~mL})$ at $-78{ }^{\circ} \mathrm{C}$ under argon, KHMDS (1.0 M solution in THF, $27.0 \mathrm{~mL}, 27.0 \mathrm{mmol}$ ) was added dropwise. After $1 \mathrm{~h}$, the reaction mixture was quenched with the saturated $\mathrm{NH}_{4} \mathrm{Cl}$ solution $(20 \mathrm{~mL})$ and warmed up to room temperature before being extracted with $\mathrm{DCM}(2 \times 100 \mathrm{~mL})$. The combined organic extracts were washed with water and brine, dried over $\mathrm{Na}_{2} \mathrm{SO}_{4}$, and concentrated in vacuum. Purification by column chromatography (PE/EA $=40: 1)$ gave $21 \mathrm{a}(1.0 \mathrm{~g}, 86 \%, 2$ steps) as a colorless oil.

${ }^{1} \mathrm{H}$ NMR $\left(400 \mathrm{MHz}, \mathrm{CDCl}_{3}\right) \delta 6.61(\mathrm{dd}, J=10.0,1.4 \mathrm{~Hz}, 1 \mathrm{H}), 6.23(\mathrm{dd}, J=15.0,10.8 \mathrm{~Hz}, 1 \mathrm{H})$, $5.97(\mathrm{ddt}, J=17.1,10.5,5.6 \mathrm{~Hz}, 1 \mathrm{H}), 5.79(\mathrm{~d}, J=10.8 \mathrm{~Hz}, 1 \mathrm{H}), 5.48(\mathrm{dt}, J=14.8,7.3 \mathrm{~Hz}, 1 \mathrm{H}), 5.33(\mathrm{ddd}$, $J=17.2,3.1,1.5 \mathrm{~Hz}, 1 \mathrm{H}), 5.23(\mathrm{dd}, J=10.4,1.3 \mathrm{~Hz}, 1 \mathrm{H}), 4.64(\mathrm{~d}, J=5.5 \mathrm{~Hz}, 2 \mathrm{H}), 3.68(\mathrm{t}, J=7.0 \mathrm{~Hz}, 2 \mathrm{H})$, 2.64-2.47 (m, 1H), $2.24(\mathrm{t}, J=7.0 \mathrm{~Hz}, 2 \mathrm{H}), 2.14(\mathrm{t}, J=7.1 \mathrm{~Hz}, 2 \mathrm{H}), 1.85(\mathrm{~d}, J=1.3 \mathrm{~Hz}, 3 \mathrm{H}), 1.74(\mathrm{~s}, 3 \mathrm{H})$, $1.02(\mathrm{~d}, J=6.7 \mathrm{~Hz}, 3 \mathrm{H}), 0.88(\mathrm{~s}, 9 \mathrm{H}), 0.04(\mathrm{~s}, 6 \mathrm{H}) .{ }^{13} \mathrm{C}$ NMR $\left(101 \mathrm{MHz}, \mathrm{CDCl}_{3}\right) \delta 168.13,147.84,134.13$, 132.75, 129.61, 128.53, 126.49, 126.40, 117.83, 65.27, 62.39, 43.29, 40.02, 33.96, 26.09, 19.68, 18.47, 17.20, $12.73,-5.14 .[\alpha]_{\mathrm{D}}^{20}=-32.72,\left(c 0.38, \mathrm{CHCl}_{3}\right)$. HRMS (ESI+): calcd. for $\mathrm{C}_{23} \mathrm{H}_{40} \mathrm{O}_{3} \mathrm{Si}[\mathrm{M}+\mathrm{H}]^{+}, 293.2819$, found 293.2819 . 


\subsection{Allyl (R,2E,6E,8E)-11-Hydroxy-2,4,9-Trimethylundeca-2,6,8-Trienoate (22)}

To a stirred solution of 21a (1.0 g, $2.6 \mathrm{mmol})$ in dry THF (5 mL), HF/Py complex (1 mL) was added at $0{ }^{\circ} \mathrm{C}$. After being stirred for $1 \mathrm{~h}$, the mixture was quenched with a saturated aqueous solution of $\mathrm{NaHCO}_{3}$ and extracted with DCM $(20 \mathrm{~mL} \times 3)$. The combined organic layers were washed with 1 $\mathrm{M} \mathrm{HCl}$, brine, dried over $\mathrm{Na}_{2} \mathrm{SO}_{4}$, filtrated, and concentrated. The residue was purified by column chromatography on silica gel (PE/EA $=6: 1)$ to give $22(550 \mathrm{mg}, 76 \%)$ as a colorless oil.

${ }^{1} \mathrm{H}$ NMR $\left(400 \mathrm{MHz}, \mathrm{CDCl}_{3}\right) \delta 6.60(\mathrm{dd}, J=10.0,1.4 \mathrm{~Hz}, 1 \mathrm{H}), 6.24(\mathrm{dd}, J=15.0,10.8 \mathrm{~Hz}, 1 \mathrm{H})$, $5.96(\mathrm{ddt}, J=17.1,10.5,5.6 \mathrm{~Hz}, 1 \mathrm{H}), 5.85(\mathrm{~d}, J=10.8 \mathrm{~Hz}, 1 \mathrm{H}), 5.52(\mathrm{dt}, J=14.8,7.3 \mathrm{~Hz}, 1 \mathrm{H}), 5.32(\mathrm{ddd}$, $J=17.2,3.0,1.5 \mathrm{~Hz}, 1 \mathrm{H}), 5.22(\mathrm{dd}, J=10.4,1.3 \mathrm{~Hz}, 1 \mathrm{H}), 4.63(\mathrm{~d}, J=5.6 \mathrm{~Hz}, 2 \mathrm{H}), 3.69(\mathrm{t}, J=6.3 \mathrm{~Hz}, 2 \mathrm{H})$, 2.65-2.51 (m, 1H), $2.29(\mathrm{t}, J=6.3 \mathrm{~Hz}, 2 \mathrm{H}), 2.15(\mathrm{t}, J=7.0 \mathrm{~Hz}, 2 \mathrm{H}), 1.84(\mathrm{~d}, J=1.4 \mathrm{~Hz}, 3 \mathrm{H}), 1.75(\mathrm{~s}, 3 \mathrm{H})$, $1.54(\mathrm{~s}, 1 \mathrm{H}), 1.01(\mathrm{~d}, J=6.7 \mathrm{~Hz}, 3 \mathrm{H}) .{ }^{13} \mathrm{C}$ NMR $\left(101 \mathrm{MHz}, \mathrm{CDCl}_{3}\right) \delta 168.09,147.69,132.93,132.70,130.49$, $128.14,127.38,126.53,117.82,65.26,60.49,42.95,39.97,33.84,19.67,16.50,12.72 .[\alpha]_{\mathrm{D}}^{20}=-38.23,(c 0.96$, $\mathrm{CHCl}_{3}$ ). HRMS (ESI+): calcd. for $\mathrm{C}_{17} \mathrm{H}_{26} \mathrm{O}_{3}[\mathrm{M}+\mathrm{H}]^{+}, 279.1955$, found 279.1954.

\subsection{Allyl (2E,4R,6E,8E,11R)-11-Hydroxy-2,4,9-Trimethyl-13-Oxotetradeca-2,6,8-Trienoate (24a)}

To the above alcohol $22(200 \mathrm{mg}, 0.72 \mathrm{mmol})$ in dry DCM $\left(5 \mathrm{~mL}, 0{ }^{\circ} \mathrm{C}\right), \mathrm{DMP}(610 \mathrm{mg}, 1.44 \mathrm{mmol})$ and $\mathrm{NaHCO}_{3}(240 \mathrm{mg}, 2.9 \mathrm{mmol})$ was added sequentially. After being stirred for $30 \mathrm{~min}$, the mixture was carefully quenched with a solution of saturated aqueous $\mathrm{NaHCO}_{3}$ and $\mathrm{Na}_{2} \mathrm{~S}_{2} \mathrm{O}_{3}$. The resulting mixture was extracted with $\mathrm{DCM}(20 \mathrm{~mL} \times 3)$ and the combined organic layers were washed with brine, dried over $\mathrm{Na}_{2} \mathrm{SO}_{4}$, and concentrated. The crude aldehyde 23 was used without future purification.

To a stirred solution of (+)-IPCBCl $(1.8 \mathrm{M}$ in heptane, $1.08 \mathrm{mmol}, 0.6 \mathrm{~mL})$ in dry ether $(3 \mathrm{~mL})$ at $-0{ }^{\circ} \mathrm{C}$ under argon, $\mathrm{Et}_{3} \mathrm{~N}(0.2 \mathrm{~mL}, 1.44 \mathrm{mmol})$ and acetone $(80 \mathrm{uL}, 1.08 \mathrm{mmol})$ were added sequentially. After $1 \mathrm{~h}$ stirring at $-0{ }^{\circ} \mathrm{C}$, aldehyde 23 in ether $(2 \mathrm{~mL})$ was added at $-78{ }^{\circ} \mathrm{C}$. The reaction was continued further for $1 \mathrm{~h}$ at $-78^{\circ} \mathrm{C}$ and another $12 \mathrm{~h}$ at $-20^{\circ} \mathrm{C}$ prior to quenching with a mixture of PH 7 buffer $(1 \mathrm{~mL})$, methanol $(1 \mathrm{~mL})$, and $\mathrm{H}_{2} \mathrm{O}_{2}(1 \mathrm{~mL})$. The mixture was warmed up to room temperature before being extracted with ether $(2 \times 10 \mathrm{~mL})$. The combined organic extracts were washed with water and brine, dried over $\mathrm{Na}_{2} \mathrm{SO}_{4}$, and concentrated in vacuum. Purification by column chromatography $(\mathrm{PE} / \mathrm{EA}=4: 1)$ created $\mathbf{2 4 a}(132 \mathrm{mg}, 55 \%)$ as a colorless oil.

${ }^{1} \mathrm{H}$ NMR $\left(400 \mathrm{MHz}, \mathrm{CDCl}_{3}\right) \delta 6.60(\mathrm{dd}, J=10.0,1.2 \mathrm{~Hz}, 1 \mathrm{H}), 6.22(\mathrm{dd}, J=15.0,10.8 \mathrm{~Hz}, 1 \mathrm{H})$, $5.96(\mathrm{ddt}, J=17.1,10.5,5.6 \mathrm{~Hz}, 1 \mathrm{H}), 5.83(\mathrm{~d}, J=10.8 \mathrm{~Hz}, 1 \mathrm{H}), 5.52(\mathrm{dt}, J=14.8,7.3 \mathrm{~Hz}, 1 \mathrm{H}), 5.32(\mathrm{dd}$, $J=17.2,1.4 \mathrm{~Hz}, 1 \mathrm{H}), 5.23(\mathrm{dd}, J=10.4,1.1 \mathrm{~Hz}, 1 \mathrm{H}), 4.64(\mathrm{~d}, J=5.5 \mathrm{~Hz}, 2 \mathrm{H}), 4.20(\mathrm{tt}, J=11.6,5.9 \mathrm{~Hz}, 1 \mathrm{H})$, $2.79(\mathrm{~s}, 1 \mathrm{H}), 2.66-2.47(\mathrm{~m}, 3 \mathrm{H}), 2.24(\mathrm{dd}, J=13.4,7.5 \mathrm{~Hz}, 1 \mathrm{H}), 2.19-2.07(\mathrm{~m}, 6 \mathrm{H}), 1.84(\mathrm{~d}, J=1.2 \mathrm{~Hz}, 3 \mathrm{H})$, $1.75(\mathrm{~s}, 3 \mathrm{H}), 1.02(\mathrm{~d}, J=6.7 \mathrm{~Hz}, 3 \mathrm{H}) .{ }^{13} \mathrm{C}$ NMR $\left(101 \mathrm{MHz}, \mathrm{CDCl}_{3}\right) \delta 209.56,168.10,147.68,132.82,132.72$, $130.79,128.10,127.99,126.58,117.85,65.91,65.29,49.62,47.13,40.02,33.86,30.98,19.72,16.89,12.75$. $[\alpha]_{\mathrm{D}}^{20}=-33.92,\left(c 0.34, \mathrm{CHCl}_{3}\right)$. HRMS (ESI+): calcd. for $\mathrm{C}_{20} \mathrm{H}_{30} \mathrm{O}_{4}[\mathrm{M}+\mathrm{H}]^{+}, 335.2217$, found 335.2217.

\subsection{Allyl (2E,4R,6E,8E,11S)-11-Hydroxy-2,4,9-Trimethyl-13-Oxotetradeca-2,6,8-Trienoate (24b)}

To a stirred solution of (-)-IPCBCl (1.7 M in heptane, $1.08 \mathrm{mmol}, 0.64 \mathrm{~mL})$ in dry ether $(3 \mathrm{~mL})$ at $0{ }^{\circ} \mathrm{C}$ under argon, $\mathrm{Et}_{3} \mathrm{~N}(0.2 \mathrm{~mL}, 1.44 \mathrm{mmol})$ and acetone $(80 \mathrm{uL}, 1.08 \mathrm{mmol})$ were added sequentially. After $1 \mathrm{~h}$ stirring at $0^{\circ} \mathrm{C}$, aldehyde 23 in ether $(2 \mathrm{~mL})$ was added at $-78^{\circ} \mathrm{C}$. The reaction was continued further for $1 \mathrm{~h}$ at $-78{ }^{\circ} \mathrm{C}$ and another $12 \mathrm{~h}$ at $-20^{\circ} \mathrm{C}$ prior to quenching with a mixture of $\mathrm{PH} 7 \mathrm{buffer}$ $(1 \mathrm{~mL})$, methanol $(1 \mathrm{~mL})$, and $\mathrm{H}_{2} \mathrm{O}_{2}(1 \mathrm{~mL})$. The mixture was warmed up to room temperature before being extracted with ether $(2 \times 10 \mathrm{~mL})$. The combined organic extracts were washed with water and brine, dried over $\mathrm{Na}_{2} \mathrm{SO}_{4}$, and concentrated in vacuum. Purification by column chromatography (PE/EA $=4: 1)$ provided $\mathbf{2 4 b}(142 \mathrm{mg}, 59 \%)$ as a colorless oil.

${ }^{1} \mathrm{H}$ NMR $\left(400 \mathrm{MHz}, \mathrm{CDCl}_{3}\right) \delta 6.60(\mathrm{dd}, J=10.0,1.2 \mathrm{~Hz}, 1 \mathrm{H}), 6.23(\mathrm{dd}, J=15.0,10.8 \mathrm{~Hz}, 1 \mathrm{H})$, $5.96(\mathrm{ddt}, J=17.1,10.5,5.6 \mathrm{~Hz}, 1 \mathrm{H}), 5.83(\mathrm{~d}, J=10.8 \mathrm{~Hz}, 1 \mathrm{H}), 5.53(\mathrm{dt}, J=14.8,7.3 \mathrm{~Hz}, 1 \mathrm{H})$, $5.32(\mathrm{dd}, J=17.2,1.4 \mathrm{~Hz}, 1 \mathrm{H}), 5.23(\mathrm{dd}, J=10.4,1.1 \mathrm{~Hz}, 1 \mathrm{H}), 4.64(\mathrm{~d}, J=5.5 \mathrm{~Hz}, 2 \mathrm{H}), 4.29-4.12$ $(\mathrm{m}, 1 \mathrm{H}), 2.66-2.51(\mathrm{~m}, 3 \mathrm{H}), 2.23(\mathrm{dd}, J=13.5,7.6 \mathrm{~Hz}, 1 \mathrm{H}), 2.19-2.08(\mathrm{~m}, 6 \mathrm{H}), 1.84(\mathrm{~d}, J=1.2 \mathrm{~Hz}, 3 \mathrm{H})$, 
$1.75(\mathrm{~s}, 3 \mathrm{H}), 1.02(\mathrm{~d}, J=6.7 \mathrm{~Hz}, 3 \mathrm{H}) .{ }^{13} \mathrm{C}$ NMR $\left(101 \mathrm{MHz}, \mathrm{CDCl}_{3}\right) \delta 209.53,168.10,147.67,132.83,132.72$, $130.76,128.12,127.98,126.57,117.86,65.92,65.29,49.66,47.11,39.97,33.86,30.98,19.69,16.91,12.74$. $[\alpha]_{\mathrm{D}}^{20}=-26.04,\left(c\right.$ 0.37, $\left.\mathrm{CHCl}_{3}\right)$. HRMS (ESI+): calcd. for $\mathrm{C}_{20} \mathrm{H}_{30} \mathrm{O}_{4}[\mathrm{M}+\mathrm{H}]^{+}, 335.2217$, found 335.2216.

\subsection{Allyl (2E,4R,6E,8E,11R)-11-((Tert-Butyldimethylsilyl)oxy)-2,4,9-Trimethyl-13-Oxotetradeca-2,6,8-Trienoate (25a)}

To a stirred solution of compound $24 \mathrm{a}(132 \mathrm{mg}, 0.4 \mathrm{mmol})$ in dry DCM $(3 \mathrm{~mL})$ at $-78{ }^{\circ} \mathrm{C}$ under argon, 2,6-lutidine $(0.23 \mathrm{~mL}, 2 \mathrm{mmol})$ and TBSOTf $(0.35 \mathrm{~mL}, 1.5 \mathrm{mmol})$ were added sequentially. After $1 \mathrm{~h}$, the reaction mixture was quenched with aqueous $\mathrm{NaHCO}_{3}(5 \mathrm{~mL})$ and warmed up to room temperature before being extracted with DCM $(2 \times 10 \mathrm{~mL})$. The combined organic extracts were washed with $1 \mathrm{M} \mathrm{HCl}$ and brine, dried over $\mathrm{Na}_{2} \mathrm{SO}_{4}$, and concentrated in vacuum. Purification by column chromatography $(\mathrm{PE} / \mathrm{EA}=40: 1)$ created $25 \mathrm{a}(160 \mathrm{mg}, 89 \%)$ as a colorless oil.

${ }^{1} \mathrm{H}$ NMR $\left(400 \mathrm{MHz}, \mathrm{CDCl}_{3}\right) \delta 6.60(\mathrm{dd}, J=10.0,1.3 \mathrm{~Hz}, 1 \mathrm{H}), 6.19(\mathrm{dd}, J=15.0,10.8 \mathrm{~Hz}, 1 \mathrm{H}), 5.96$ $(\mathrm{ddt}, J=17.1,10.5,5.6 \mathrm{~Hz}, 1 \mathrm{H}), 5.75(\mathrm{~d}, J=10.8 \mathrm{~Hz}, 1 \mathrm{H}), 5.48(\mathrm{dt}, J=14.8,7.3 \mathrm{~Hz}, 1 \mathrm{H}), 5.33(\mathrm{dd}, J=$ $17.2,1.5 \mathrm{~Hz}, 1 \mathrm{H}), 5.23(\mathrm{dd}, J=10.4,1.2 \mathrm{~Hz}, 1 \mathrm{H}), 4.64(\mathrm{~d}, J=5.6 \mathrm{~Hz}, 2 \mathrm{H}), 4.38-4.20(\mathrm{~m}, 1 \mathrm{H}), 2.67-2.41$ $(\mathrm{m}, 3 \mathrm{H}), 2.29-2.20(\mathrm{~m}, 1 \mathrm{H}), 2.19-2.00(\mathrm{~m}, 6 \mathrm{H}), 1.84(\mathrm{~d}, J=1.1 \mathrm{~Hz}, 3 \mathrm{H}), 1.73(\mathrm{~s}, 3 \mathrm{H}), 1.01(\mathrm{~d}, J=6.7 \mathrm{~Hz}$, $3 \mathrm{H}), 0.85(\mathrm{~s}, 9 \mathrm{H}), 0.03(\mathrm{~d}, J=8.1 \mathrm{~Hz}, 6 \mathrm{H}) .{ }^{13} \mathrm{C}$ NMR $\left(101 \mathrm{MHz}, \mathrm{CDCl}_{3}\right) \delta 208.04,168.10,147.75,133.24$, $132.74,130.28,128.31,128.07,126.53,117.86,68.06,65.29,50.86,48.64,40.00,33.93,31.85,25.96,19.67$, 18.12, 17.30, 12.74, $-4.41,-4.71 .[\alpha]_{\mathrm{D}}^{20}=-40.90,\left(c 0.26, \mathrm{CHCl}_{3}\right)$. HRMS (ESI+): calcd. for $\mathrm{C}_{26} \mathrm{H}_{44} \mathrm{O}_{4} \mathrm{Si}$ $[\mathrm{M}+\mathrm{H}]^{+}, 449.3082$, found 449.3078 .

\subsection{Allyl (2E,4R,6E,8E,11S)-11-((Tert-Butyldimethylsilyl)oxy)-2,4,9-Trimethyl-13-Oxotetradeca-2,6,8-Trienoate (25b)}

The procedure was identical to $25 \mathbf{a}$. Compound $25 \mathbf{b}(160 \mathrm{mg}, 85 \%)$ was obtained as a colorless oil.

${ }^{1} \mathrm{H}$ NMR $\left(400 \mathrm{MHz}, \mathrm{CDCl}_{3}\right) \delta 6.60(\mathrm{dd}, J=10.0,1.3 \mathrm{~Hz}, 1 \mathrm{H}), 6.19(\mathrm{dd}, J=15.0,10.8 \mathrm{~Hz}, 1 \mathrm{H}), 5.96$ $(\mathrm{ddt}, J=17.1,10.5,5.6 \mathrm{~Hz}, 1 \mathrm{H}), 5.74(\mathrm{~d}, J=10.8 \mathrm{~Hz}, 1 \mathrm{H}), 5.48(\mathrm{dt}, J=14.8,7.3 \mathrm{~Hz}, 1 \mathrm{H}), 5.32(\mathrm{dd}, J=17.2$, $1.5 \mathrm{~Hz}, 1 \mathrm{H}), 5.23(\mathrm{dd}, J=10.4,1.3 \mathrm{~Hz}, 1 \mathrm{H}), 4.64(\mathrm{~d}, J=5.5 \mathrm{~Hz}, 2 \mathrm{H}), 4.35-4.23(\mathrm{~m}, 1 \mathrm{H}), 2.66-2.42(\mathrm{~m}, 3 \mathrm{H})$, $2.23(\mathrm{dd}, J=13.2,5.7 \mathrm{~Hz}, 1 \mathrm{H}), 2.19-2.05(\mathrm{~m}, 6 \mathrm{H}), 1.84(\mathrm{~d}, J=1.2 \mathrm{~Hz}, 3 \mathrm{H}), 1.73(\mathrm{~s}, 3 \mathrm{H}), 1.01(\mathrm{~d}, J=6.7 \mathrm{~Hz}$, $3 \mathrm{H}), 0.84(\mathrm{~s}, 9 \mathrm{H}), 0.02(\mathrm{~d}, J=7.1 \mathrm{~Hz}, 6 \mathrm{H}) .{ }^{13} \mathrm{C}$ NMR $\left(101 \mathrm{MHz}, \mathrm{CDCl}_{3}\right) \delta 208.07,168.09,147.76,133.25$, 132.74, 130.27, 128.31, 128.04, 126.52, 117.85, 68.09, 65.28, 50.84, 48.60, 40.04, 33.92, 31.84, 25.95, 19.71, $18.11,17.33,12.73,-4.42,-4.74 .[\alpha]_{\mathrm{D}}^{20}=-17.13,\left(c 0.51, \mathrm{CHCl}_{3}\right)$. HRMS (ESI+): calcd. for $\mathrm{C}_{26} \mathrm{H}_{44} \mathrm{O}_{4} \mathrm{Si}$ $[\mathrm{M}+\mathrm{H}]^{+}, 449.3082$, found 449.3079 .

\subsection{Allyl (2E,4R,6E,8E,11R,13S)-11-((Tert-Butyldimethylsilyl)Oxy)-13-Hydroxy-2,4,9-Trimethyltetradeca-2,6,8-Trienoate (26a)}

To a solution of $(R)$-Me-CBS (1 M in toluene, $0.05 \mathrm{~mL}, 0.05 \mathrm{mmol}$ ) in dry THF ( $5 \mathrm{~mL}$ ) was slowly added $\mathrm{BH}_{3}$.DMS (12 uL, $\left.0.13 \mathrm{mmol}\right)$ at $-40{ }^{\circ} \mathrm{C}$. After being stirred for $30 \mathrm{~min}$ at the same temperature, a solution of $25 \mathrm{a}(57 \mathrm{mg}, 0.13 \mathrm{mmol})$ in THF $(2 \mathrm{~mL})$ was slowly added. After being stirred for $2 \mathrm{~h}$ at $-40{ }^{\circ} \mathrm{C}$, the mixture was diluted with $\mathrm{MeOH}$. The resulting mixture was concentrated and extracted with DCM $(30 \mathrm{~mL} \times 3)$. The combined organic layers were washed with brine, dried, filtrated, and concentrated. The residue was purified by column chromatography on silica gel (PE/EA = 15:1) to give a mixture of $\mathbf{2 6 a}$ and $\mathbf{2 6} \mathbf{b}(4: 1,48 \mathbf{m g}, 83 \%)$ as a colorless oil (pure major isomer $\mathbf{2 6 a}$ can be obtained by repeating the purification on silica gel).

${ }^{1} \mathrm{H}$ NMR $\left(400 \mathrm{MHz}, \mathrm{CDCl}_{3}\right) \delta 6.60(\mathrm{~d}, J=9.9 \mathrm{~Hz}, 1 \mathrm{H}), 6.18(\mathrm{dd}, J=14.7,11.0 \mathrm{~Hz}, 1 \mathrm{H}), 5.96(\mathrm{ddt}$, $J=17.1,10.5,5.6 \mathrm{~Hz}, 1 \mathrm{H}), 5.77(\mathrm{~d}, J=10.8 \mathrm{~Hz}, 1 \mathrm{H}), 5.49(\mathrm{dt}, J=14.8,7.3 \mathrm{~Hz}, 1 \mathrm{H}), 5.32(\mathrm{dd}, J=17.2$, $1.4 \mathrm{~Hz}, 1 \mathrm{H}), 5.23(\mathrm{dd}, J=10.5,1.0 \mathrm{~Hz}, 1 \mathrm{H}), 4.63(\mathrm{~d}, J=5.5 \mathrm{~Hz}, 2 \mathrm{H}), 4.27-4.06(\mathrm{~m}, 2 \mathrm{H}), 2.66-2.47(\mathrm{~m}, 1 \mathrm{H})$, $2.35(\mathrm{dd}, J=13.4,6.3 \mathrm{~Hz}, 1 \mathrm{H}), 2.23(\mathrm{dd}, J=13.3,7.6 \mathrm{~Hz}, 1 \mathrm{H}), 2.16(\mathrm{dd}, J=20.8,13.7 \mathrm{~Hz}, 2 \mathrm{H}), 1.84(\mathrm{~s}, 3 \mathrm{H})$, $1.71(\mathrm{~s}, 3 \mathrm{H}), 1.61(\mathrm{ddd}, J=14.0,10.0,3.7 \mathrm{~Hz}, 1 \mathrm{H}), 1.48(\mathrm{ddd}, J=14.5,9.4,3.7 \mathrm{~Hz}, 1 \mathrm{H}), 1.14(\mathrm{~d}, J=6.2 \mathrm{~Hz}$, $3 \mathrm{H}), 0.99(\mathrm{~d}, J=11.9 \mathrm{~Hz}, 3 \mathrm{H}), 0.88(\mathrm{~s}, 9 \mathrm{H}), 0.07(\mathrm{~d}, J=18.8 \mathrm{~Hz}, 6 \mathrm{H}) .{ }^{13} \mathrm{C}$ NMR $\left(101 \mathrm{MHz}, \mathrm{CDCl}_{3}\right) \delta$ 168.12, 147.74, 133.01, 132.72, 130.26, 128.29, 127.95, 126.52, 117.86, 70.36, 65.29, 64.58, 46.98, 43.26, 40.03, $33.91,25.95,23.98,19.68,18.06,17.15,12.76,-4.51,-4.70 .[\alpha]_{\mathrm{D}}^{20}=-17.67,\left(c 0.1, \mathrm{CHCl}_{3}\right)$. HRMS (ESI+): calcd. for $\mathrm{C}_{26} \mathrm{H}_{46} \mathrm{O}_{4} \mathrm{Si}[\mathrm{M}+\mathrm{H}]^{+}, 451.3238$, found 451.3241 . 
To a solution of (S)-Me-CBS ( $1 \mathrm{M}$ in toluene, $0.1 \mathrm{~mL}, 0.1 \mathrm{mmol})$ in dry THF ( $5 \mathrm{~mL}), \mathrm{BH}_{3}$.DMS ( $24 \mathrm{uL}, 0.25 \mathrm{mmol}$ ) was slowly added at $-40^{\circ} \mathrm{C}$. After being stirred for $30 \mathrm{~min}$ at the same temperature, a solution of $25 \mathrm{a}(110 \mathrm{mg}, 0.24 \mathrm{mmol})$ in THF $(2 \mathrm{~mL})$ was slowly added. After being stirred for $2 \mathrm{~h}$ at $-40^{\circ} \mathrm{C}$, the mixture was diluted with $\mathrm{MeOH}$. The resulting mixture was concentrated and extracted with DCM $(30 \mathrm{~mL} \times 3)$. The combined organic layers were washed with brine, dried, filtrated, and concentrated. The residue was purified by column chromatography on silica gel (PE/EA $=15: 1$ ) to create $\mathbf{2 6 \mathbf { b }}(92 \mathrm{mg}, 85 \%)$ as a colorless oil.

${ }^{1} \mathrm{H}$ NMR $\left(400 \mathrm{MHz}, \mathrm{CDCl}_{3}\right) \delta 6.60(\mathrm{dd}, J=10.0,1.3 \mathrm{~Hz}, 1 \mathrm{H}), 6.19(\mathrm{dd}, J=15.0,10.8 \mathrm{~Hz}, 1 \mathrm{H})$, 6.04-5.92 (m, 1H), $5.77(\mathrm{~d}, J=10.8 \mathrm{~Hz}, 1 \mathrm{H}), 5.51(\mathrm{dd}, J=14.9,7.4 \mathrm{~Hz}, 1 \mathrm{H}), 5.33(\mathrm{dd}, J=17.2,1.5 \mathrm{~Hz}$, $1 \mathrm{H}), 5.23(\mathrm{dd}, J=10.4,1.3 \mathrm{~Hz}, 1 \mathrm{H}), 4.64(\mathrm{~d}, J=5.5 \mathrm{~Hz}, 2 \mathrm{H}), 4.01(\mathrm{dq}, J=13.0,4.3 \mathrm{~Hz}, 1 \mathrm{H}), 3.96-3.83$ $(\mathrm{m}, 1 \mathrm{H}), 3.18(\mathrm{~s}, 1 \mathrm{H}), 2.66-2.50(\mathrm{~m}, 1 \mathrm{H}), 2.32(\mathrm{dd}, J=13.1,4.6 \mathrm{~Hz}, 1 \mathrm{H}), 2.12(\mathrm{dt}, J=13.2,7.9 \mathrm{~Hz}, 3 \mathrm{H})$, $1.84(\mathrm{~d}, J=1.1 \mathrm{~Hz}, 3 \mathrm{H}), 1.72(\mathrm{~s}, 3 \mathrm{H}), 1.59-1.52(\mathrm{~m}, 1 \mathrm{H}), 1.47-1.37(\mathrm{~m}, 1 \mathrm{H}), 1.14(\mathrm{~d}, J=6.2 \mathrm{~Hz}, 3 \mathrm{H}), 1.02$ $(\mathrm{d}, J=6.7 \mathrm{~Hz}, 3 \mathrm{H}), 0.89(\mathrm{~s}, 9 \mathrm{H}), 0.12(\mathrm{~d}, J=8.4 \mathrm{~Hz}, 6 \mathrm{H}) .{ }^{13} \mathrm{C}$ NMR $\left(101 \mathrm{MHz}, \mathrm{CDCl}_{3}\right) \delta 168.12,147.73$, $132.79,132.72,130.34,128.23,127.93,126.54,117.86,72.22,67.43,65.29,49.26,44.82,40.01,33.91,25.95$, 23.70, 19.70, 18.03, 17.28, 12.75, -3.77, -4.55. $[\alpha]_{\mathrm{D}}^{20}=-40.33,\left(c 0.35, \mathrm{CHCl}_{3}\right)$. HRMS (ESI+): calcd. for $\mathrm{C}_{26} \mathrm{H}_{46} \mathrm{O}_{4} \mathrm{Si}[\mathrm{M}+\mathrm{H}]^{+}, 451.3238$, found 451.3241 .

\subsection{Allyl (2E,4R,6E,8E,11S,13R)-11-((Tert-Butyldimethylsilyl)Oxy)-13-Hydroxy-2,4,9-Trimethyltetradeca-2,6,8-Trienoate (26c)}

To a solution of (S)-Me-CBS ( $1 \mathrm{M}$ in toluene, $0.05 \mathrm{~mL}, 0.05 \mathrm{mmol})$ in dry THF ( $5 \mathrm{~mL}), \mathrm{BH}_{3}$.DMS $\left(12 \mathrm{uL}, 0.13 \mathrm{mmol}\right.$ ) was slowly added at $-40^{\circ} \mathrm{C}$. After being stirred for $30 \mathrm{~min}$ at the same temperature, a solution of $25 \mathbf{b}$ ( $55 \mathrm{mg}, 0.12 \mathrm{mmol}$ ) in THF ( $2 \mathrm{~mL}$ ) was slowly added. After being stirred for $2 \mathrm{~h}$ at $-40{ }^{\circ} \mathrm{C}$, the mixture was diluted with $\mathrm{MeOH}$. The resulting mixture was concentrated and extracted with DCM $(30 \mathrm{~mL} \times 3)$. The combined organic layers were washed with brine, dried, filtrated, and concentrated. The residue was purified by column chromatography on silica gel (PE/EA $=15: 1$ ) to give a mixture of $\mathbf{2 6 c}$ and $\mathbf{2 6 d}(3.6: 1,44 \mathrm{mg}, 80 \%$ ) as a colorless oil (pure major isomer $\mathbf{2 6 c}$ can be obtained by repeating the purification on silica gel).

${ }^{1}$ H NMR $\left(400 \mathrm{MHz}, \mathrm{CDCl}_{3}\right) \delta 6.60(\mathrm{dd}, J=10.0,1.3 \mathrm{~Hz}, 1 \mathrm{H}), 6.19(\mathrm{dd}, J=15.0,10.9 \mathrm{~Hz}, 1 \mathrm{H}), 5.96$ $(\mathrm{ddt}, J=17.1,10.5,5.6 \mathrm{~Hz}, 1 \mathrm{H}), 5.77(\mathrm{~d}, J=10.8 \mathrm{~Hz}, 1 \mathrm{H}), 5.49(\mathrm{dt}, J=14.8,7.3 \mathrm{~Hz}, 1 \mathrm{H}), 5.32(\mathrm{dd}, J=17.2$, $1.5 \mathrm{~Hz}, 1 \mathrm{H}), 5.23(\mathrm{dd}, J=10.4,1.2 \mathrm{~Hz}, 1 \mathrm{H}), 4.64(\mathrm{~d}, J=5.5 \mathrm{~Hz}, 2 \mathrm{H}), 4.23-4.07(\mathrm{~m}, 2 \mathrm{H}), 3.36(\mathrm{~s}, 1 \mathrm{H})$, 2.67-2.49 (m, 1H), $2.35(\mathrm{dd}, J=13.3,6.2 \mathrm{~Hz}, 1 \mathrm{H}), 2.29-2.21(\mathrm{~m}, 1 \mathrm{H}), 2.14(\mathrm{t}, J=7.0 \mathrm{~Hz}, 2 \mathrm{H}), 1.84(\mathrm{~d}$, $J=1.1 \mathrm{~Hz}, 3 \mathrm{H}), 1.71(\mathrm{~s}, 3 \mathrm{H}), 1.64-1.56(\mathrm{~m}, 1 \mathrm{H}), 1.49(\mathrm{ddd}, J=14.5,9.5,3.7 \mathrm{~Hz}, 1 \mathrm{H}), 1.14(\mathrm{~d}, J=6.2 \mathrm{~Hz}$, $3 \mathrm{H}), 1.01(\mathrm{~d}, J=6.6 \mathrm{~Hz}, 3 \mathrm{H}), 0.88(\mathrm{~s}, 9 \mathrm{H}), 0.06(\mathrm{~d}, J=20.4 \mathrm{~Hz}, 6 \mathrm{H}) .{ }^{13} \mathrm{C}$ NMR $\left(101 \mathrm{MHz}, \mathrm{CDCl}_{3}\right) \delta 168.09$, $147.74,133.01,132.71,130.27,128.27,127.94,126.52,117.86,70.43,65.29,64.58,46.92,43.25,40.04,33.93$, $25.95,23.98,19.73,18.06,17.21,12.73,-4.52,-4.71 .[\alpha]_{\mathrm{D}}^{20}=-14.83,\left(c 0.1, \mathrm{CHCl}_{3}\right)$. HRMS (ESI+): calcd. for $\mathrm{C}_{26} \mathrm{H}_{46} \mathrm{O}_{4} \mathrm{Si}[\mathrm{M}+\mathrm{H}]^{+}, 451.3238$, found 451.3240 .

\subsection{Allyl (2E,4R,6E,8E,11S,13S)-11-((Tert-Butyldimethylsilyl)Oxy)-13-Hydroxy-2,4,9-Trimethyltetradeca-2,6,8-Trienoate (26d)}

To a solution of (R)-Me-CBS ( $1 \mathrm{M}$ in toluene, $0.1 \mathrm{~mL}, 0.1 \mathrm{mmol})$ in dry THF $(5 \mathrm{~mL}), \mathrm{BH}_{3}$.DMS ( $24 \mathrm{uL}, 0.25 \mathrm{mmol}$ ) was slowly added at $-40^{\circ} \mathrm{C}$. After being stirred for $30 \mathrm{~min}$ at the same temperature, a solution of $\mathbf{2 5 b}(113 \mathrm{mg}, 0.25 \mathrm{mmol})$ in THF $(2 \mathrm{~mL})$ was slowly added. After being stirred for $2 \mathrm{~h}$ at $-40{ }^{\circ} \mathrm{C}$, the mixture was diluted with $\mathrm{MeOH}$. The resulting mixture was concentrated and extracted with $\mathrm{DCM}(30 \mathrm{~mL} \times 3)$. The combined organic layers were washed with brine, dried, filtrated, and concentrated. The residue was purified by column chromatography on silica gel (PE/EA $=15: 1$ ) to provide $26 \mathrm{~d}(100 \mathrm{mg}, 88 \%)$ as a colorless oil.

${ }^{1} \mathrm{H}$ NMR $\left(400 \mathrm{MHz}, \mathrm{CDCl}_{3}\right) \delta 6.60(\mathrm{dd}, J=10.0,1.3 \mathrm{~Hz}, 1 \mathrm{H}), 6.19(\mathrm{dd}, J=15.0,10.8 \mathrm{~Hz}, 1 \mathrm{H}), 5.96$ $(\mathrm{ddt}, J=17.1,10.5,5.6 \mathrm{~Hz}, 1 \mathrm{H}), 5.76(\mathrm{~d}, J=10.8 \mathrm{~Hz}, 1 \mathrm{H}), 5.50(\mathrm{dt}, J=14.8,7.3 \mathrm{~Hz}, 1 \mathrm{H}), 5.32(\mathrm{dd}, J=17.2$, $1.5 \mathrm{~Hz}, 1 \mathrm{H}), 5.23(\mathrm{dd}, J=10.4,1.3 \mathrm{~Hz}, 1 \mathrm{H}), 4.64(\mathrm{~d}, J=5.5 \mathrm{~Hz}, 2 \mathrm{H}), 4.11-3.98(\mathrm{~m}, 1 \mathrm{H}), 3.95-3.82(\mathrm{~m}, 1 \mathrm{H})$, $3.12(\mathrm{~s}, 1 \mathrm{H}), 2.67-2.51(\mathrm{~m}, 1 \mathrm{H}), 2.32(\mathrm{dd}, J=13.2,4.7 \mathrm{~Hz}, 1 \mathrm{H}), 2.19-2.06(\mathrm{~m}, 3 \mathrm{H}), 1.84(\mathrm{~d}, J=1.2 \mathrm{~Hz}, 3 \mathrm{H})$, 
$1.71(\mathrm{~s}, 3 \mathrm{H}), 1.56(\mathrm{dt}, J=14.4,3.2 \mathrm{~Hz}, 1 \mathrm{H}), 1.46-1.38(\mathrm{~m}, 1 \mathrm{H}), 1.14(\mathrm{~d}, J=6.2 \mathrm{~Hz}, 3 \mathrm{H}), 1.02(\mathrm{~d}, J=6.7 \mathrm{~Hz}$, 3H), 0.89 (s, 9H), $0.11(\mathrm{~d}, J=8.9 \mathrm{~Hz}, 6 \mathrm{H}) .{ }^{13} \mathrm{C}$ NMR $\left(101 \mathrm{MHz}, \mathrm{CDCl}_{3}\right) \delta 168.10,147.74,132.78,132.71$, 130.32, 128.22, 127.91, 126.53, 117.84, 72.26, 67.41, 65.28, 49.21, 44.81, 40.03, 33.90, 25.95, 23.70, 19.72, $18.02,17.33,12.74,-3.78,-4.56 .[\alpha]_{\mathrm{D}}^{20}=-15.29,\left(c 0.63, \mathrm{CHCl}_{3}\right)$. HRMS (ESI+): calcd. for $\mathrm{C}_{26} \mathrm{H}_{46} \mathrm{O}_{4} \mathrm{Si}$ $[\mathrm{M}+\mathrm{H}]^{+}, 451.3238$, found 451.3228 .

\subsection{Synthetic Procedure of $\mathbf{2 7 a}-\mathbf{2 7 d}$}

To a stirred solution of 26a ( $35 \mathrm{mg})$ in dry THF $(2 \mathrm{~mL})$, the HF/Py complex $(0.7 \mathrm{~mL})$ was added at $0{ }^{\circ} \mathrm{C}$. After being stirred for $1 \mathrm{~h}$, the mixture was quenched with a saturated aqueous solution of $\mathrm{NaHCO}_{3}$ and extracted with $\mathrm{DCM}(10 \mathrm{~mL} \times 3)$. The combined organic layers were washed with $1 \mathrm{M} \mathrm{HCl}$, brine, dried over $\mathrm{Na}_{2} \mathrm{SO}_{4}$, filtrated, and concentrated. The residue was purified by a column chromatography on silica gel (PE/EA $=2: 1)$ to create $27 \mathrm{a}(22 \mathrm{mg}, 84 \%)$ as a colorless oil.

${ }^{1} \mathrm{H}$ NMR $\left(400 \mathrm{MHz}, \mathrm{CDCl}_{3}\right) \delta 6.64-6.56(\mathrm{~m}, 1 \mathrm{H}), 6.23(\mathrm{dd}, J=15.0,10.8 \mathrm{~Hz}, 1 \mathrm{H}), 5.96(\mathrm{ddt}, J=17.1$, $10.5,5.6 \mathrm{~Hz}, 1 \mathrm{H}), 5.84(\mathrm{~d}, J=10.8 \mathrm{~Hz}, 1 \mathrm{H}), 5.54(\mathrm{dt}, J=14.8,7.3 \mathrm{~Hz}, 1 \mathrm{H}), 5.32(\mathrm{dd}, J=17.2,1.4 \mathrm{~Hz}, 1 \mathrm{H})$, $5.23(\mathrm{dd}, J=10.5,0.9 \mathrm{~Hz}, 1 \mathrm{H}), 4.64(\mathrm{~d}, J=5.5 \mathrm{~Hz}, 2 \mathrm{H}), 4.13-4.02(\mathrm{~m}, 1 \mathrm{H}), 4.02-3.92(\mathrm{~m}, 1 \mathrm{H}), 2.65-2.51$ $(\mathrm{m}, 1 \mathrm{H}), 2.24-2.10(\mathrm{~m}, 4 \mathrm{H}), 1.84(\mathrm{~d}, J=1.3 \mathrm{~Hz}, 3 \mathrm{H}), 1.75(\mathrm{~s}, 3 \mathrm{H}), 1.61-1.55(\mathrm{~m}, 1 \mathrm{H}), 1.55-1.47(\mathrm{~m}, 1 \mathrm{H})$, $1.20(\mathrm{~d}, J=6.2 \mathrm{~Hz}, 3 \mathrm{H}), 1.02(\mathrm{~d}, J=6.7 \mathrm{~Hz}, 3 \mathrm{H}) .{ }^{13} \mathrm{C} \mathrm{NMR}\left(101 \mathrm{MHz}, \mathrm{CDCl}_{3}\right) \delta 168.11,147.65,132.71$, 132.58, 130.99, 128.31, 128.00, 126.60, 117.87, 70.45, 68.91, 65.30, 48.84, 44.80, 40.00, 33.83, 24.07, 19.72, 16.88, 12.75. $[\alpha]_{\mathrm{D}}^{20}=-29.76,\left(c 0.34, \mathrm{CHCl}_{3}\right)$. HRMS (ESI+): calcd. for $\mathrm{C}_{20} \mathrm{H}_{32} \mathrm{O}_{4}[\mathrm{M}+\mathrm{Na}]^{+}, 337.2373$, found 337.2375 .

Compound $27 \mathrm{~b}(20.9 \mathrm{mg}, 80 \%)$ was obtained as a colorless oil. ${ }^{1} \mathrm{H}$ NMR $\left(400 \mathrm{MHz}, \mathrm{CDCl}_{3}\right) \delta 6.60$ $(\mathrm{dd}, J=10.0,1.3 \mathrm{~Hz}, 1 \mathrm{H}), 6.23(\mathrm{dd}, J=15.0,10.8 \mathrm{~Hz}, 1 \mathrm{H}), 5.96(\mathrm{ddt}, J=17.1,10.5,5.6 \mathrm{~Hz}, 1 \mathrm{H}), 5.85$ $(\mathrm{d}, J=10.7 \mathrm{~Hz}, 1 \mathrm{H}), 5.54(\mathrm{dt}, J=14.8,7.3 \mathrm{~Hz}, 1 \mathrm{H}), 5.32(\mathrm{dd}, J=17.2,1.5 \mathrm{~Hz}, 1 \mathrm{H}), 5.23(\mathrm{dd}, J=10.4,1.2 \mathrm{~Hz}$, $1 \mathrm{H}), 4.64(\mathrm{~d}, J=5.5 \mathrm{~Hz}, 2 \mathrm{H}), 4.21-4.12(\mathrm{~m}, 1 \mathrm{H}), 4.08(\mathrm{ddd}, J=12.4,7.8,5.3 \mathrm{~Hz}, 1 \mathrm{H}), 2.65-2.51(\mathrm{~m}, 1 \mathrm{H})$, 2.22-2.18 (m, 2H), $2.16(\mathrm{~d}, J=7.2 \mathrm{~Hz}, 2 \mathrm{H}), 1.84(\mathrm{~d}, J=1.3 \mathrm{~Hz}, 3 \mathrm{H}), 1.76(\mathrm{~s}, 3 \mathrm{H}), 1.67-1.54(\mathrm{~m}, 2 \mathrm{H})$, $1.23(\mathrm{~d}, J=6.3 \mathrm{~Hz}, 3 \mathrm{H}), 1.02(\mathrm{~d}, J=6.7 \mathrm{~Hz}, 3 \mathrm{H}) .{ }^{13} \mathrm{C} \mathrm{NMR}\left(101 \mathrm{MHz}, \mathrm{CDCl}_{3}\right) \delta 168.11,147.65,133.00$, 132.71, 130.92, 128.15, 128.03, 126.59, 117.86, 66.73, 65.47, 65.30, 48.14, 44.09, 40.01, 33.84, 23.69, 19.72, 16.81, 12.75. $[\alpha]_{\mathrm{D}}^{20}=-14.00,\left(c 0.05, \mathrm{CHCl}_{3}\right)$. HRMS (ESI+): calcd. for $\mathrm{C}_{20} \mathrm{H}_{32} \mathrm{O}_{4}[\mathrm{M}+\mathrm{Na}]^{+}, 337.2373$, found 337.2377.

Compound $27 \mathrm{c}(22 \mathrm{mg}, 84 \%)$ was obtained as a colorless oil. ${ }^{1} \mathrm{H}$ NMR $\left(400 \mathrm{MHz}, \mathrm{CDCl}_{3}\right) \delta 6.60$ $(\mathrm{dd}, J=10.0,1.3 \mathrm{~Hz}, 1 \mathrm{H}), 6.23(\mathrm{dd}, J=14.9,10.8 \mathrm{~Hz}, 1 \mathrm{H}), 5.96(\mathrm{ddt}, J=17.1,10.5,5.6 \mathrm{~Hz}, 1 \mathrm{H}), 5.84$ $(\mathrm{d}, J=10.8 \mathrm{~Hz}, 1 \mathrm{H}), 5.54(\mathrm{dt}, J=14.9,7.3 \mathrm{~Hz}, 1 \mathrm{H}), 5.33(\mathrm{dd}, J=17.2,1.5 \mathrm{~Hz}, 1 \mathrm{H}), 5.23(\mathrm{dd}, J=10.4,1.2 \mathrm{~Hz}$, $1 \mathrm{H}), 4.64(\mathrm{~d}, J=5.5 \mathrm{~Hz}, 2 \mathrm{H}), 4.10-4.02(\mathrm{~m}, 1 \mathrm{H}), 4.01-3.94(\mathrm{~m}, 1 \mathrm{H}), 2.62-2.52(\mathrm{~m}, 1 \mathrm{H}), 2.20-2.11(\mathrm{~m}, 4 \mathrm{H})$, $1.84(\mathrm{~d}, J=1.3 \mathrm{~Hz}, 3 \mathrm{H}), 1.75(\mathrm{~s}, 3 \mathrm{H}), 1.61-1.55(\mathrm{~m}, 1 \mathrm{H}), 1.54-1.46(\mathrm{~m}, 1 \mathrm{H}), 1.20(\mathrm{~d}, J=6.2 \mathrm{~Hz}, 3 \mathrm{H}), 1.02$ $(\mathrm{d}, J=6.7 \mathrm{~Hz}, 3 \mathrm{H}) .{ }^{13} \mathrm{C}$ NMR $\left(101 \mathrm{MHz}, \mathrm{CDCl}_{3}\right) \delta 168.12,147.64,132.71,132.57,130.99,128.32,128.01$, $126.60,117.87,70.45,68.91,65.31,48.84,44.81,39.99,33.85,24.07,19.70,16.88,12.75 .[\alpha]_{\mathrm{D}}^{20}=-29.37$, (c 0.32, $\mathrm{CHCl}_{3}$ ). HRMS (ESI+): calcd. for $\mathrm{C}_{20} \mathrm{H}_{32} \mathrm{O}_{4}[\mathrm{M}+\mathrm{Na}]^{+}, 337.2373$, found 337.2374.

Compound $27 \mathrm{~d}(21.4 \mathrm{mg}, 82 \%)$ was obtained as a colorless oil. ${ }^{1} \mathrm{H} \mathrm{NMR}\left(400 \mathrm{MHz}, \mathrm{CDCl}_{3}\right) \delta$ $6.23(\mathrm{dd}, J=15.0,10.8 \mathrm{~Hz}, 1 \mathrm{H}), 5.96(\mathrm{ddt}, J=17.1,10.5,5.6 \mathrm{~Hz}, 1 \mathrm{H}), 5.86(\mathrm{~d}, J=10.8 \mathrm{~Hz}, 1 \mathrm{H}), 5.54$ $(\mathrm{dt}, J=14.8,7.3 \mathrm{~Hz}, 1 \mathrm{H}), 5.33(\mathrm{dd}, J=17.2,1.5 \mathrm{~Hz}, 1 \mathrm{H}), 5.23(\mathrm{dd}, J=10.4,1.3 \mathrm{~Hz}, 1 \mathrm{H}), 4.64(\mathrm{~d}, J=5.5 \mathrm{~Hz}$, $2 \mathrm{H}), 4.21-4.11(\mathrm{~m}, 1 \mathrm{H}), 4.12-4.02(\mathrm{~m}, 1 \mathrm{H}), 2.65-2.51(\mathrm{~m}, 1 \mathrm{H}), 2.23-2.18(\mathrm{~m}, 2 \mathrm{H}), 2.15(\mathrm{t}, J=7.2 \mathrm{~Hz}, 2 \mathrm{H})$, $1.84(\mathrm{~d}, J=1.3 \mathrm{~Hz}, 3 \mathrm{H}), 1.76(\mathrm{~s}, 3 \mathrm{H}), 1.65-1.56(\mathrm{~m}, 2 \mathrm{H}), 1.23(\mathrm{~d}, J=6.3 \mathrm{~Hz}, 3 \mathrm{H}), 1.02(\mathrm{~d}, J=6.6 \mathrm{~Hz}, 3 \mathrm{H})$. ${ }^{13} \mathrm{C}$ NMR $\left(101 \mathrm{MHz}, \mathrm{CDCl}_{3}\right) \delta 168.12,147.64,132.99,132.72,130.95,128.18,128.04,126.60,117.87,66.72$, $65.48,65.31,48.14,44.10,39.99,33.86,23.69,19.70,16.82,12.76 .[\alpha]_{\mathrm{D}}^{20}=-17.62,\left(c 0.32, \mathrm{CHCl}_{3}\right)$. HRMS (ESI+): calcd. for $\mathrm{C}_{20} \mathrm{H}_{32} \mathrm{O}_{4}[\mathrm{M}+\mathrm{Na}]^{+}, 337.2373$, found 337.2374.

\subsection{Synthetic Procedure of $\mathbf{2 8 a} \mathbf{- 2 8 d}$}

To a stirred solution of compound $27 \mathrm{a}(22 \mathrm{mg}, 0.065 \mathrm{mmol})$ in dry acetone $(2 \mathrm{~mL})$ under argon, PTSA $\cdot \mathrm{H}_{2} \mathrm{O}(1.14 \mathrm{mg}, 0.006 \mathrm{mmol})$ and 2,2-dimethylpropane $(0.08 \mathrm{~mL}, 0.65 \mathrm{mmol})$ were added sequentially. After $1 \mathrm{~h}$, the reaction mixture was quenched with a saturated aqueous solution of 
$\mathrm{NaHCO}_{3}$ and extracted with DCM $(2 \times 10 \mathrm{~mL})$. The combined organic extracts were washed with water and brine, dried over $\mathrm{Na}_{2} \mathrm{SO}_{4}$, and concentrated in vacuum. Purification by column chromatography $(\mathrm{PE} / \mathrm{EA}=20: 1)$ provided $28 \mathrm{a}(23 \mathrm{mg}, 93 \%)$ as a colorless oil.

${ }^{1} \mathrm{H}$ NMR $\left(400 \mathrm{MHz}, \mathrm{CDCl}_{3}\right) \delta 6.61(\mathrm{dd}, J=9.9,1.3 \mathrm{~Hz}, 1 \mathrm{H}), 6.23(\mathrm{dd}, J=15.0,10.8 \mathrm{~Hz}, 1 \mathrm{H}), 5.96$ $(\mathrm{ddt}, J=17.1,10.5,5.6 \mathrm{~Hz}, 1 \mathrm{H}), 5.80(\mathrm{~d}, J=10.8 \mathrm{~Hz}, 1 \mathrm{H}), 5.50(\mathrm{dt}, J=14.8,7.3 \mathrm{~Hz}, 1 \mathrm{H}), 5.32(\mathrm{dd}, J=17.2$, $1.5 \mathrm{~Hz}, 1 \mathrm{H}), 5.23(\mathrm{dd}, J=10.4,1.3 \mathrm{~Hz}, 1 \mathrm{H}), 4.64(\mathrm{~d}, J=5.5 \mathrm{~Hz}, 2 \mathrm{H}), 4.04-3.88(\mathrm{~m}, 2 \mathrm{H}), 2.65-2.50(\mathrm{~m}, 1 \mathrm{H})$, $2.30(\mathrm{dd}, J=13.6,5.9 \mathrm{~Hz}, 1 \mathrm{H}), 2.15(\mathrm{t}, J=7.1 \mathrm{~Hz}, 2 \mathrm{H}), 2.06(\mathrm{dd}, J=13.6,7.0 \mathrm{~Hz}, 1 \mathrm{H}), 1.84(\mathrm{~d}, J=1.1 \mathrm{~Hz}$, $3 \mathrm{H}), 1.74(\mathrm{~s}, 3 \mathrm{H}), 1.49-1.42(\mathrm{~m}, 4 \mathrm{H}), 1.41-1.34(\mathrm{~m}, 4 \mathrm{H}), 1.15(\mathrm{~d}, J=6.1 \mathrm{~Hz}, 3 \mathrm{H}), 1.02(\mathrm{~d}, J=6.7 \mathrm{~Hz}, 3 \mathrm{H})$. ${ }^{13} \mathrm{C}$ NMR $\left(101 \mathrm{MHz}, \mathrm{CDCl}_{3}\right) \delta 168.11,147.77,133.12,132.72,129.98,128.39,127.15,126.52,117.83,98.61$, $67.97,65.34,65.27,46.85,40.00,38.60,33.90,30.46,22.38,19.94,19.69,17.34,12.74 .[\alpha]_{\mathrm{D}}^{20}=-30.22,(c 0.26$, $\mathrm{CHCl}_{3}$ ). HRMS (ESI+): calcd. for $\mathrm{C}_{23} \mathrm{H}_{36} \mathrm{O}_{4}[\mathrm{M}+\mathrm{Na}]^{+}, 377.2686$, found 377.2689.

Compound $28 \mathbf{b}(20.8 \mathrm{mg}, 89 \%)$ was obtained as a colorless oil. ${ }^{1} \mathrm{H}$ NMR $\left(400 \mathrm{MHz}, \mathrm{CDCl}_{3}\right) \delta 6.61$ $(\mathrm{dd}, J=10.0,1.3 \mathrm{~Hz}, 1 \mathrm{H}), 6.23(\mathrm{dd}, J=15.0,10.8 \mathrm{~Hz}, 1 \mathrm{H}), 5.96(\mathrm{ddt}, J=17.1,10.5,5.6 \mathrm{~Hz}, 1 \mathrm{H}), 5.81$ $(\mathrm{d}, J=10.7 \mathrm{~Hz}, 1 \mathrm{H}), 5.49(\mathrm{dt}, J=14.8,7.3 \mathrm{~Hz}, 1 \mathrm{H}), 5.33(\mathrm{dd}, J=17.2,1.5 \mathrm{~Hz}, 1 \mathrm{H}), 5.23(\mathrm{dd}, J=10.4,1.3$ $\mathrm{Hz}, 1 \mathrm{H}), 4.64(\mathrm{~d}, J=5.5 \mathrm{~Hz}, 2 \mathrm{H}), 4.04-3.88(\mathrm{~m}, 2 \mathrm{H}), 2.64-2.51(\mathrm{~m}, 1 \mathrm{H}), 2.31(\mathrm{dd}, J=14.1,6.9 \mathrm{~Hz}, 1 \mathrm{H})$, 2.22-2.07 (m, 3H), $1.84(\mathrm{~d}, J=1.3 \mathrm{~Hz}, 3 \mathrm{H}), 1.74(\mathrm{~s}, 3 \mathrm{H}), 1.63-1.57(\mathrm{~m}, 2 \mathrm{H}), 1.35(\mathrm{~s}, 6 \mathrm{H}), 1.18(\mathrm{~d}, J=6.3 \mathrm{~Hz}$, $3 \mathrm{H}), 1.02(\mathrm{~d}, J=6.7 \mathrm{~Hz}, 3 \mathrm{H}) .{ }^{13} \mathrm{C}$ NMR $\left(101 \mathrm{MHz}, \mathrm{CDCl}_{3}\right) \delta 168.13,147.79,133.39,132.74,129.93,128.43$, $126.83,126.52,117.84,100.32,65.40,65.28,62.94,46.16,40.00,39.83,33.93,25.24,25.13,21.86,19.70$, $17.07,12.75 .[\alpha]_{\mathrm{D}}^{20}=-47.32,\left(c 0.11, \mathrm{CHCl}_{3}\right)$. HRMS (ESI+): calcd. for $\mathrm{C}_{23} \mathrm{H}_{36} \mathrm{O}_{4}[\mathrm{M}+\mathrm{Na}]^{+}, 377.2686$, found 377.2684 .

Compound 28c (22 mg, 90\%) was obtained as a colorless oil. ${ }^{1} \mathrm{H}$ NMR $\left(400 \mathrm{MHz}, \mathrm{CDCl}_{3}\right) \delta 6.61$ $(\mathrm{dd}, J=9.9,1.3 \mathrm{~Hz}, 1 \mathrm{H}), 6.23(\mathrm{dd}, J=15.0,10.8 \mathrm{~Hz}, 1 \mathrm{H}), 5.96(\mathrm{ddt}, J=17.1,10.5,5.6 \mathrm{~Hz}, 1 \mathrm{H}), 5.80$ $(\mathrm{d}, J=10.8 \mathrm{~Hz}, 1 \mathrm{H}), 5.50(\mathrm{dt}, J=14.8,7.3 \mathrm{~Hz}, 1 \mathrm{H}), 5.32(\mathrm{dd}, J=17.2,1.5 \mathrm{~Hz}, 1 \mathrm{H}), 5.23(\mathrm{dd}, J=10.4$, $1.2 \mathrm{~Hz}, 1 \mathrm{H}), 4.64(\mathrm{~d}, J=5.5 \mathrm{~Hz}, 2 \mathrm{H}), 4.02-3.88(\mathrm{~m}, 2 \mathrm{H}), 2.66-2.50(\mathrm{~m}, 1 \mathrm{H}), 2.30(\mathrm{dd}, J=13.6,5.9 \mathrm{~Hz}, 1 \mathrm{H})$, $2.15(\mathrm{t}, J=7.1 \mathrm{~Hz}, 2 \mathrm{H}), 2.06(\mathrm{dd}, J=13.7,7.0 \mathrm{~Hz}, 1 \mathrm{H}), 1.84(\mathrm{~d}, J=1.2 \mathrm{~Hz}, 3 \mathrm{H}), 1.74(\mathrm{~s}, 3 \mathrm{H}), 1.49-1.42$ $(\mathrm{m}, 4 \mathrm{H}), 1.41-1.34(\mathrm{~m}, 4 \mathrm{H}), 1.15(\mathrm{~d}, J=6.1 \mathrm{~Hz}, 3 \mathrm{H}), 1.02(\mathrm{~d}, J=6.7 \mathrm{~Hz}, 3 \mathrm{H}) .{ }^{13} \mathrm{C}$ NMR $\left(101 \mathrm{MHz}, \mathrm{CDCl}_{3}\right)$ $\delta$ 168.10, 147.76, 133.12, 132.72, 129.96, 128.39, 127.11, 126.51, 117.83, 98.60, 67.97, 65.34, 65.27, 46.81, $40.00,38.60,33.89,30.45,22.38,19.94,19.70,17.35,12.73 .[\alpha]_{\mathrm{D}}^{20}=-25.76,\left(c 0.69, \mathrm{CHCl}_{3}\right)$. HRMS (ESI+): calcd. for $\mathrm{C}_{23} \mathrm{H}_{36} \mathrm{O}_{4}[\mathrm{M}+\mathrm{Na}]^{+}, 377.2686$, found 377.2685.

Compound $28 \mathrm{~d}(21.5 \mathrm{mg}, 90 \%)$ was obtained as a colorless oil. ${ }^{1} \mathrm{H} \mathrm{NMR}\left(400 \mathrm{MHz}, \mathrm{CDCl}_{3}\right) \delta$ $6.61(\mathrm{dd}, J=10.0,1.3 \mathrm{~Hz}, 1 \mathrm{H}), 6.23(\mathrm{dd}, J=15.0,10.8 \mathrm{~Hz}, 1 \mathrm{H}), 5.96(\mathrm{ddt}, J=17.1,10.5,5.6 \mathrm{~Hz}, 1 \mathrm{H})$, $5.49(\mathrm{dt}, J=14.8,7.3 \mathrm{~Hz}, 1 \mathrm{H}), 5.32(\mathrm{dd}, J=17.2,1.5 \mathrm{~Hz}, 1 \mathrm{H}), 5.23(\mathrm{dd}, J=10.4,1.3 \mathrm{~Hz}, 1 \mathrm{H}), 4.64$ $(\mathrm{d}, J=5.5 \mathrm{~Hz}, 2 \mathrm{H}), 4.04-3.86(\mathrm{~m}, 2 \mathrm{H}), 2.65-2.48(\mathrm{~m}, 1 \mathrm{H}), 2.31(\mathrm{dd}, J=14.1,7.0 \mathrm{~Hz}, 1 \mathrm{H}), 2.20-2.06$ $(\mathrm{m}, 3 \mathrm{H}), 1.84(\mathrm{~d}, J=1.3 \mathrm{~Hz}, 3 \mathrm{H}), 1.74(\mathrm{~s}, 3 \mathrm{H}), 1.68-1.57(\mathrm{~m}, 2 \mathrm{H}), 1.35(\mathrm{~s}, 6 \mathrm{H}), 1.18(\mathrm{~d}, J=6.3 \mathrm{~Hz}, 3 \mathrm{H}), 1.02$ $(\mathrm{d}, J=6.7 \mathrm{~Hz}, 3 \mathrm{H}) .{ }^{13} \mathrm{C}$ NMR $\left(101 \mathrm{MHz}, \mathrm{CDCl}_{3}\right) \delta 168.11,147.78,133.38,132.73,129.90,128.42,126.79$, $126.51,117.83,100.31,65.38,65.27,62.93,46.13,40.00,39.84,33.92,25.23,25.11,21.85,19.70,17.07,12.74$. $[\alpha]_{\mathrm{D}}^{20}=-17.71,\left(c 0.23, \mathrm{CHCl}_{3}\right)$. HRMS (ESI+): calcd. for $\mathrm{C}_{23} \mathrm{H}_{36} \mathrm{O}_{4}[\mathrm{M}+\mathrm{Na}]^{+}, 377.2686$, found 377.2692.

\subsection{Synthetic Procedure of $\mathbf{2 9 a}-\mathbf{2 9 d}$}

To a stirred solution of compound 26a (48 mg, $0.11 \mathrm{mmol})$ in dry DCM (3 mL) and 4A molecular sieve under argon, the Proton Sponge $(107 \mathrm{mg}, 0.5 \mathrm{mmol})$ and trimethyloxonium tetrafluoroborate $(60 \mathrm{mg}, 0.4 \mathrm{mmol}$ ) were added sequentially. After $1 \mathrm{~h}$, the reaction mixture was quenched with $1 \mathrm{M} \mathrm{HCl}$ $(10 \mathrm{~mL})$ and extracted with DCM $(2 \times 10 \mathrm{~mL})$. The combined organic extracts were washed with water and brine, dried over $\mathrm{Na}_{2} \mathrm{SO}_{4}$, and concentrated in vacuum. Purification by column chromatography $(\mathrm{PE} / \mathrm{EA}=40: 1)$ created 29a $(38 \mathrm{mg}, 77 \%)$ as a colorless oil.

${ }^{1} \mathrm{H}$ NMR $\left(400 \mathrm{MHz}, \mathrm{CDCl}_{3}\right) \delta 6.60(\mathrm{~d}, J=9.9 \mathrm{~Hz}, 1 \mathrm{H}), 6.20(\mathrm{dd}, J=15.0,10.8 \mathrm{~Hz}, 1 \mathrm{H}), 5.96$ $(\mathrm{ddt}, J=17.1,10.5,5.6 \mathrm{~Hz}, 1 \mathrm{H}), 5.75(\mathrm{~d}, J=10.8 \mathrm{~Hz}, 1 \mathrm{H}), 5.47(\mathrm{dt}, J=14.8,7.3 \mathrm{~Hz}, 1 \mathrm{H}), 5.28(\mathrm{ddd}, J=13.8$, 11.6, $1.3 \mathrm{~Hz}, 2 \mathrm{H}), 4.64(\mathrm{~d}, J=5.6 \mathrm{~Hz}, 2 \mathrm{H}), 4.00(\mathrm{tdd}, J=8.7,5.4,3.2 \mathrm{~Hz}, 1 \mathrm{H}), 3.54-3.37(\mathrm{~m}, 1 \mathrm{H}), 3.28$ $(\mathrm{d}, J=2.2 \mathrm{~Hz}, 3 \mathrm{H}), 2.71-2.44(\mathrm{~m}, 1 \mathrm{H}), 2.36-2.21(\mathrm{~m}, 1 \mathrm{H}), 2.21-2.01(\mathrm{~m}, 3 \mathrm{H}), 1.84(\mathrm{~d}, J=1.2 \mathrm{~Hz}, 3 \mathrm{H}), 1.72$ $(\mathrm{s}, 3 \mathrm{H}), 1.62-1.54(\mathrm{~m}, 1 \mathrm{H}), 1.37-1.28(\mathrm{~m}, 1 \mathrm{H}), 1.11(\mathrm{~d}, J=6.1 \mathrm{~Hz}, 3 \mathrm{H}), 1.01(\mathrm{~d}, J=6.6 \mathrm{~Hz}, 3 \mathrm{H}), 0.88(\mathrm{~s}, 9 \mathrm{H})$, 
$0.05(\mathrm{~d}, J=6.1 \mathrm{~Hz}, 6 \mathrm{H}) .{ }^{13} \mathrm{C}$ NMR $\left(101 \mathrm{MHz}, \mathrm{CDCl}_{3}\right) \delta 168.12,147.85,133.80,132.75,129.65,128.52$, 127.56, 126.47, 117.85, 73.13, 67.86, 65.27, 55.62, 49.18, 44.92, 39.99, 33.96, 26.08, 19.64, 19.38, 18.20, 17.36, $12.72,-3.96,-4.53 .[\alpha]_{\mathrm{D}}^{20}=-38.67,\left(c 0.05, \mathrm{CHCl}_{3}\right)$. HRMS (ESI+): calcd. for $\mathrm{C}_{27} \mathrm{H}_{48} \mathrm{O}_{4} \mathrm{Si}[\mathrm{M}+\mathrm{H}]^{+}$, 465.3395, found 465.3388 .

Compound $\mathbf{2 9 b}(72 \mathrm{mg}, 76 \%)$ was obtained as a colorless oil. ${ }^{1} \mathbf{H}$ NMR $\left(500 \mathrm{MHz}, \mathrm{CDCl}_{3}\right) \delta 6.61$ $(\mathrm{dd}, J=9.9,1.1 \mathrm{~Hz}, 1 \mathrm{H}), 6.20(\mathrm{dd}, J=14.9,10.9 \mathrm{~Hz}, 1 \mathrm{H}), 5.96(\mathrm{ddt}, J=17.1,10.5,5.6 \mathrm{~Hz}, 1 \mathrm{H}), 5.77$ $(\mathrm{d}, J=10.8 \mathrm{~Hz}, 1 \mathrm{H}), 5.46(\mathrm{dt}, J=14.8,7.3 \mathrm{~Hz}, 1 \mathrm{H}), 5.33(\mathrm{dd}, J=17.2,1.5 \mathrm{~Hz}, 1 \mathrm{H}), 5.23(\mathrm{dd}, J=10.4,1.2 \mathrm{~Hz}$, $1 \mathrm{H}), 4.64(\mathrm{dd}, J=5.5,1.1 \mathrm{~Hz}, 2 \mathrm{H}), 3.93-3.83(\mathrm{~m}, 1 \mathrm{H}), 3.41(\mathrm{dd}, J=12.5,6.3 \mathrm{~Hz}, 1 \mathrm{H}), 3.29(\mathrm{~s}, 3 \mathrm{H}), 2.64-2.47$ $(\mathrm{m}, 1 \mathrm{H}), 2.28-2.05(\mathrm{~m}, 4 \mathrm{H}), 1.84(\mathrm{~d}, J=1.3 \mathrm{~Hz}, 3 \mathrm{H}), 1.72(\mathrm{~s}, 4 \mathrm{H}), 1.48-1.39(\mathrm{~m}, 1 \mathrm{H}), 1.11(\mathrm{~d}, J=6.1 \mathrm{~Hz}$, $3 \mathrm{H}), 1.01(\mathrm{~d}, J=6.7 \mathrm{~Hz}, 3 \mathrm{H}), 0.86(\mathrm{~s}, 9 \mathrm{H}), 0.02(\mathrm{~d}, J=9.8 \mathrm{~Hz}, 6 \mathrm{H}) .{ }^{13} \mathrm{C} \mathrm{NMR}\left(126 \mathrm{MHz}, \mathrm{CDCl}_{3}\right) \delta 168.14$, 147.87, 133.66, 132.73, 129.73, 128.47, 127.73, 126.45, 117.85, 74.24, 68.48, 65.28, 55.97, 48.38, 44.21, 40.01, $33.97,26.01,19.64,19.43,18.16,17.33,12.74,-4.15,-4.47 .[\alpha]_{\mathrm{D}}^{20}=-34.83,\left(\right.$ c $\left.0.38, \mathrm{CHCl}_{3}\right)$. HRMS (ESI+): calcd. for $\mathrm{C}_{27} \mathrm{H}_{48} \mathrm{O}_{4} \mathrm{Si}[\mathrm{M}+\mathrm{H}]^{+}, 465.3395$, found 465.3391 .

Compound $29 \mathrm{c}(32 \mathrm{mg}, 71 \%)$ was obtained as a colorless oil. ${ }^{1} \mathbf{H}$ NMR $\left(400 \mathrm{MHz}, \mathrm{CDCl}_{3}\right) \delta$ $6.59(\mathrm{~d}, J=9.7 \mathrm{~Hz}, 1 \mathrm{H}), 6.18(\mathrm{dd}, J=15.0,10.9 \mathrm{~Hz}, 1 \mathrm{H}), 5.94(\mathrm{ddt}, J=17.1,10.5,5.6 \mathrm{~Hz}, 1 \mathrm{H}), 5.73$ $(\mathrm{d}, J=10.7 \mathrm{~Hz}, 1 \mathrm{H}), 5.45(\mathrm{dt}, J=14.7,7.2 \mathrm{~Hz}, 1 \mathrm{H}), 5.31(\mathrm{dd}, J=17.2,1.1 \mathrm{~Hz}, 1 \mathrm{H}), 5.21(\mathrm{~d}, J=10.5 \mathrm{~Hz}, 1 \mathrm{H})$, $4.62(\mathrm{~d}, J=5.5 \mathrm{~Hz}, 2 \mathrm{H}), 3.98(\mathrm{dt}, J=16.1,6.0 \mathrm{~Hz}, 1 \mathrm{H}), 3.51-3.35(\mathrm{~m}, 1 \mathrm{H}), 3.26(\mathrm{~s}, 3 \mathrm{H}), 2.62-2.44(\mathrm{~m}, 1 \mathrm{H})$, $2.27(\mathrm{ddd}, J=19.7,13.8,9.4 \mathrm{~Hz}, 1 \mathrm{H}), 2.18-2.01(\mathrm{~m}, 3 \mathrm{H}), 1.82(\mathrm{~s}, 3 \mathrm{H}), 1.70(\mathrm{~s}, 3 \mathrm{H}), 1.60-1.52(\mathrm{~m}, 1 \mathrm{H})$, $1.37-1.25(\mathrm{~m}, 1 \mathrm{H}), 1.09(\mathrm{~d}, J=6.1 \mathrm{~Hz}, 3 \mathrm{H}), 0.99(\mathrm{~d}, J=6.6 \mathrm{~Hz}, 3 \mathrm{H}), 0.86(\mathrm{~s}, 9 \mathrm{H}), 0.03(\mathrm{~d}, J=6.8 \mathrm{~Hz}$, 6H). ${ }^{13} \mathrm{C}$ NMR $\left(101 \mathrm{MHz}, \mathrm{CDCl}_{3}\right) \delta 168.11,147.86,133.79,132.74,129.66,128.51,127.55,126.46,117.84$, 73.13, 67.86, 65.27, 55.63, 49.18, 44.91, 40.05, 33.97, 26.08, 19.71, 19.38, 18.20, 17.39, 12.72, -3.96, -4.54. $[\alpha]_{\mathrm{D}}^{20}=-26.17,\left(c \mathrm{c} .1, \mathrm{CHCl}_{3}\right)$. HRMS (ESI+): calcd. for $\mathrm{C}_{27} \mathrm{H}_{48} \mathrm{O}_{4} \mathrm{Si}[\mathrm{M}+\mathrm{H}]^{+}, 465.3395$, found 465.3389 .

Compound $29 \mathrm{~d}(72 \mathrm{mg}, 70 \%)$ was obtained as a colorless oil. ${ }^{1} \mathbf{H}$ NMR $\left(400 \mathrm{MHz}, \mathrm{CDCl}_{3}\right) \delta 6.61$ $(\mathrm{dd}, J=10.0,1.2 \mathrm{~Hz}, 1 \mathrm{H}), 6.20(\mathrm{dd}, J=15.0,10.9 \mathrm{~Hz}, 1 \mathrm{H}), 5.96(\mathrm{ddt}, J=17.1,10.5,5.6 \mathrm{~Hz}, 1 \mathrm{H}), 5.77(\mathrm{~d}, J=$ $10.8 \mathrm{~Hz}, 1 \mathrm{H}), 5.46(\mathrm{dt}, J=14.7,7.2 \mathrm{~Hz}, 1 \mathrm{H}), 5.33(\mathrm{dd}, J=17.2,1.5 \mathrm{~Hz}, 1 \mathrm{H}), 5.23(\mathrm{dd}, J=10.4,1.2 \mathrm{~Hz}, 1 \mathrm{H})$, $4.64(\mathrm{~d}, J=5.5 \mathrm{~Hz}, 2 \mathrm{H}), 3.94-3.79(\mathrm{~m}, 1 \mathrm{H}), 3.51-3.36(\mathrm{~m}, 1 \mathrm{H}), 3.29(\mathrm{~s}, 3 \mathrm{H}), 2.70-2.50(\mathrm{~m}, 1 \mathrm{H}), 2.25-2.07$ $(\mathrm{m}, 4 \mathrm{H}), 1.85(\mathrm{~d}, J=1.3 \mathrm{~Hz}, 3 \mathrm{H}), 1.79-1.67(\mathrm{~m}, 4 \mathrm{H}), 1.45(\mathrm{~m}, 1 \mathrm{H}), 1.12(\mathrm{~d}, J=6.1 \mathrm{~Hz}, 3 \mathrm{H}), 1.01(\mathrm{~d}, J=$ $6.6 \mathrm{~Hz}, 3 \mathrm{H}), 0.86(\mathrm{~s}, 9 \mathrm{H}), 0.01(\mathrm{~d}, J=9.0 \mathrm{~Hz}, 6 \mathrm{H}) .{ }^{13} \mathrm{C}$ NMR $\left(101 \mathrm{MHz}, \mathrm{CDCl}_{3}\right) \delta 168.12,147.87,133.67$, $132.75,129.73,128.47,127.72,126.47,117.84,74.25,68.54,65.28,55.97,48.39,44.20,40.07,33.96,26.02$, $19.70,19.44,18.17,17.37,12.74,-4.15,-4.47 .[\alpha]_{\mathrm{D}}^{20}=-16.46,\left(c 0.41, \mathrm{CHCl}_{3}\right)$. HRMS (ESI+): calcd. for $\mathrm{C}_{27} \mathrm{H}_{48} \mathrm{O}_{4} \mathrm{Si}[\mathrm{M}+\mathrm{H}]^{+}, 465.3395$, found 465.3389 .

\subsection{Synthetic Procedure of $\mathbf{1} \boldsymbol{a}-\mathbf{1 d}$}

To a stirred solution of 29a in dry THF $(2 \mathrm{~mL})$, the HF/Py complex $(0.4 \mathrm{~mL})$ was added at $0{ }^{\circ} \mathrm{C}$. After being stirred for $1 \mathrm{~h}$, the mixture was quenched with a saturated aqueous solution of $\mathrm{NaHCO}_{3}$ and extracted with $\mathrm{DCM}(10 \mathrm{~mL} \times 3)$. The combined organic layers were washed with $1 \mathrm{M} \mathrm{HCl}$, brine, dried over $\mathrm{Na}_{2} \mathrm{SO}_{4}$, filtrated, and concentrated. The residue was purified by column chromatography on silica gel ( $\mathrm{PE} / \mathrm{EA}=4: 1)$ to create $\mathbf{1 a}(20 \mathrm{mg}, 70 \%)$ as a colorless oil.

${ }^{1} \mathrm{H}$ NMR $\left(400 \mathrm{MHz}, \mathrm{CDCl}_{3}\right) \delta 6.60(\mathrm{dd}, J=9.9,1.3 \mathrm{~Hz}, 1 \mathrm{H}), 6.23(\mathrm{dd}, J=15.0,10.8 \mathrm{~Hz}, 1 \mathrm{H}), 5.96$ $(\mathrm{ddt}, J=17.1,10.5,5.6 \mathrm{~Hz}, 1 \mathrm{H}), 5.83(\mathrm{~d}, J=10.8 \mathrm{~Hz}, 1 \mathrm{H}), 5.59-5.42(\mathrm{~m}, 1 \mathrm{H}), 5.32(\mathrm{dd}, J=17.2,1.5 \mathrm{~Hz}$, $1 \mathrm{H}), 5.22(\mathrm{dd}, J=10.4,1.2 \mathrm{~Hz}, 1 \mathrm{H}), 4.63(\mathrm{~d}, J=5.5 \mathrm{~Hz}, 2 \mathrm{H}), 4.10-3.98(\mathrm{~m}, 1 \mathrm{H}), 3.69-3.61(\mathrm{~m}, 1 \mathrm{H})$, $3.34(\mathrm{~s}, 3 \mathrm{H}), 2.57(\mathrm{~m}, 1 \mathrm{H}), 2.17(\mathrm{~m}, 4 \mathrm{H}), 1.84(\mathrm{~d}, J=1.3 \mathrm{~Hz}, 3 \mathrm{H}), 1.75(\mathrm{~s}, 3 \mathrm{H}), 1.59-1.55(\mathrm{~m}, 2 \mathrm{H}), 1.17$ $(\mathrm{d}, J=6.2 \mathrm{~Hz}, 3 \mathrm{H}), 1.01(\mathrm{~d}, J=6.6 \mathrm{~Hz}, 3 \mathrm{H}) .{ }^{13} \mathrm{C}$ NMR $\left(101 \mathrm{MHz}, \mathrm{CDCl}_{3}\right) \delta 168.11,147.75,133.68,132.71$, 130.36, 128.23, 127.58, 126.52, 117.85, 74.75, 66.38, 65.28, 56.34, 48.36, 42.82, 40.00, 33.89, 19.70, 18.94, 16.91, 12.73. $[\alpha]_{\mathrm{D}}^{20}=-25.83,\left(c 0.46, \mathrm{CHCl}_{3}\right)$. HRMS (ESI+): calcd. for $\mathrm{C}_{21} \mathrm{H}_{34} \mathrm{O}_{4}[\mathrm{M}+\mathrm{Na}]^{+}, 373.2349$, found 373.2346 .

Compound $\mathbf{1 b}(40 \mathrm{mg}, 74 \%)$ was obtained as a colorless oil. ${ }^{1} \mathbf{H}$ NMR $\left(400 \mathrm{MHz}, \mathrm{CDCl}_{3}\right) \delta 6.60$ $(\mathrm{dd}, J=9.9,1.1 \mathrm{~Hz}, 1 \mathrm{H}), 6.23(\mathrm{dd}, J=15.0,10.8 \mathrm{~Hz}, 1 \mathrm{H}), 5.95(\mathrm{ddt}, J=17.1,10.5,5.6 \mathrm{~Hz}, 1 \mathrm{H}), 5.82$ $(\mathrm{d}, J=10.8 \mathrm{~Hz}, 1 \mathrm{H}), 5.50(\mathrm{dt}, J=14.8,7.3 \mathrm{~Hz}, 1 \mathrm{H}), 5.32(\mathrm{dd}, J=17.2,1.5 \mathrm{~Hz}, 1 \mathrm{H}), 5.22(\mathrm{dd}, J=10.4,1.2$ $\mathrm{Hz}, 1 \mathrm{H}), 4.63(\mathrm{~d}, J=5.5 \mathrm{~Hz}, 2 \mathrm{H}), 3.98-3.87(\mathrm{~m}, 1 \mathrm{H}), 3.61-3.49(\mathrm{~m}, 1 \mathrm{H}), 3.33(\mathrm{~s}, 3 \mathrm{H}), 2.65-2.47(\mathrm{~m}, 1 \mathrm{H})$, 
2.26-2.05 (m, 4H), $1.83(\mathrm{~s}, 3 \mathrm{H}), 1.75(\mathrm{~s}, 3 \mathrm{H}), 1.59-1.50(\mathrm{~m}, 2 \mathrm{H}), 1.17(\mathrm{~d}, J=6.0 \mathrm{~Hz}, 3 \mathrm{H}), 1.01(\mathrm{~d}, J=6.7 \mathrm{~Hz}$, 3H). ${ }^{13} \mathrm{C}$ NMR $\left(101 \mathrm{MHz}, \mathrm{CDCl}_{3}\right) \delta 168.10,147.78,133.68,132.70,130.13,128.30,127.42,126.48,117.82$, $77.98,69.74,65.25,55.89,48.24,43.29,40.00,33.88,19.68,19.20,17.00,12.71 .[\alpha]_{\mathrm{D}}^{20}=-29.17,(c 0.80$, $\mathrm{CHCl}_{3}$ ). HRMS (ESI+): calcd. for $\mathrm{C}_{21} \mathrm{H}_{34} \mathrm{O}_{4}[\mathrm{M}+\mathrm{Na}]^{+}, 373.2349$, found 373.2348.

Compound 1c $(18 \mathrm{mg}, 75 \%)$ was obtained as a colorless oil. ${ }^{1} \mathbf{H}$ NMR $\left(400 \mathrm{MHz}, \mathrm{CDCl}_{3}\right) \delta 6.60$ $(\mathrm{dd}, J=9.9,1.3 \mathrm{~Hz}, 1 \mathrm{H}), 6.23(\mathrm{dd}, J=15.0,10.8 \mathrm{~Hz}, 1 \mathrm{H}), 5.96(\mathrm{ddt}, J=17.1,10.5,5.6 \mathrm{~Hz}, 1 \mathrm{H}), 5.83$ $(\mathrm{d}, J=10.8 \mathrm{~Hz}, 1 \mathrm{H}), 5.59-5.42(\mathrm{~m}, 1 \mathrm{H}), 5.32(\mathrm{dd}, J=17.2,1.5 \mathrm{~Hz}, 1 \mathrm{H}), 5.22(\mathrm{dd}, J=10.4,1.2 \mathrm{~Hz}, 1 \mathrm{H})$, $4.63(\mathrm{~d}, J=5.5 \mathrm{~Hz}, 2 \mathrm{H}), 4.10-3.98(\mathrm{~m}, 1 \mathrm{H}), 3.69-3.61(\mathrm{~m}, 1 \mathrm{H}), 3.34(\mathrm{~s}, 3 \mathrm{H}), 2.57(\mathrm{~m}, 1 \mathrm{H}), 2.17(\mathrm{~m}, 4 \mathrm{H})$, $1.84(\mathrm{~d}, J=1.3 \mathrm{~Hz}, 3 \mathrm{H}), 1.75(\mathrm{~s}, 3 \mathrm{H}), 1.59-1.55(\mathrm{~m}, 2 \mathrm{H}), 1.17(\mathrm{~d}, J=6.2 \mathrm{~Hz}, 3 \mathrm{H}), 1.01(\mathrm{~d}, J=6.6 \mathrm{~Hz}, 3 \mathrm{H})$. ${ }^{13} \mathrm{C}$ NMR $\left(101 \mathrm{MHz}, \mathrm{CDCl}_{3}\right) \delta 168.11,147.74,133.68,132.71,130.34,128.24,127.58,126.52,117.85,74.74$, $66.38,65.28,56.34,48.36,42.87,39.98,33.89,19.68,18.96,16.91,12.73 .[\alpha]_{\mathrm{D}}^{20}=-21.89,\left(c 0.52, \mathrm{CHCl}_{3}\right)$. HRMS (ESI+): calcd. for $\mathrm{C}_{21} \mathrm{H}_{34} \mathrm{O}_{4}[\mathrm{M}+\mathrm{Na}]^{+}, 373.2349$, found 373.2349.

Compound $1 \mathbf{d}(40 \mathrm{mg}, 74 \%)$ was obtained as a colorless oil. ${ }^{1} \mathbf{H}$ NMR $\left(400 \mathrm{MHz}, \mathrm{CDCl}_{3}\right) \delta 6.60$ $(\mathrm{dd}, J=9.9,1.1 \mathrm{~Hz}, 1 \mathrm{H}), 6.23(\mathrm{dd}, J=15.0,10.8 \mathrm{~Hz}, 1 \mathrm{H}), 5.95(\mathrm{ddt}, J=17.1,10.5,5.6 \mathrm{~Hz}, 1 \mathrm{H}), 5.82$ $(\mathrm{d}, J=10.8 \mathrm{~Hz}, 1 \mathrm{H}), 5.50(\mathrm{dt}, J=14.8,7.3 \mathrm{~Hz}, 1 \mathrm{H}), 5.32(\mathrm{dd}, J=17.2,1.5 \mathrm{~Hz}, 1 \mathrm{H}), 5.22(\mathrm{dd}, J=10.4,1.2$ $\mathrm{Hz}, 1 \mathrm{H}), 4.63(\mathrm{~d}, J=5.5 \mathrm{~Hz}, 2 \mathrm{H}), 3.98-3.87(\mathrm{~m}, 1 \mathrm{H}), 3.61-3.49(\mathrm{~m}, 1 \mathrm{H}), 3.33(\mathrm{~s}, 3 \mathrm{H}), 2.65-2.47(\mathrm{~m}, 1 \mathrm{H})$, 2.26-2.05 (m, 4H), $1.83(\mathrm{~s}, 3 \mathrm{H}), 1.75(\mathrm{~s}, 3 \mathrm{H}), 1.59-1.50(\mathrm{~m}, 2 \mathrm{H}), 1.17(\mathrm{~d}, J=6.0 \mathrm{~Hz}, 3 \mathrm{H}), 1.01(\mathrm{~d}, J=6.7 \mathrm{~Hz}$, 3H). ${ }^{13}$ C NMR (101 MHz, $\left.\mathrm{CDCl}_{3}\right) \delta 168.10,147.78,133.69,132.70,130.11,128.31,127.41,126.48,117.83$, $77.96,69.75,65.26,55.89,48.22,43.30,39.96,33.88,19.66,19.20,17.04,12.71 .[\alpha]_{\mathrm{D}}^{20}=-38.68,(c 0.76$, $\mathrm{CHCl}_{3}$ ). HRMS (ESI+): calcd. for $\mathrm{C}_{21} \mathrm{H}_{34} \mathrm{O}_{4}[\mathrm{M}+\mathrm{Na}]^{+}, 373.2349$, found 373.2350. Detailed NMR data tables of 1a-1d are in the Supplementary Material.

\section{Conclusions}

Asymmetric synthesis of the alotamdie fragment C15-C32 was established and four diastereomers were achieved concisely. Boron-mediated enantioselective aldol reaction led to a good diastereoselectivity and Julia-Kocienski olefination constructed the diene part in excellent $E / Z$ selectivity and yield. A careful NMR comparison between four isomers and natural alotamide suggested the relative structure.

Supplementary Materials: A supplementary file is available online at http:/ /www.mdpi.com/1660-3397/16/ $11 / 414 /$ s1. Supplementary Information shows the NMR spectra of the synthetic compounds and the NMR data tables of 1a-1d.

Author Contributions: Y.G. and C.-g.H. designed the experiments. H.-y.S., Y.X., P.H., Z.-Q.G., and Y.-h.L. performed the experiments. H.-y.S. and C.-g.H. wrote the paper.

Funding: We acknowledge financial support from the National Natural Science Foundation of China for Young Scientists [no. 81602998] and the National Science and Technology Major Project of the Ministry of Science and Technology of China (No. 2018ZX09731016-003 and No. 2018ZX09201001-001-008).

Conflicts of Interest: The authors declare no conflict of interest.

\section{References}

1. Nagarajan, M.; Maruthanayagam, V.; Sundararaman, M. A review of pharmacological and toxicological potentials of marine cyanobacterial metabolites. J. Appl. Toxicol. 2012, 32, 153-185. [CrossRef] [PubMed]

2. Mayer, A.M.; Rodriguez, A.D.; Taglialatela-Scafati, O.; Fusetani, N. Marine pharmacology in 2009-2011: Marine compounds with antibacterial, antidiabetic, antifungal, anti-inflammatory, antiprotozoal, antituberculosis, and antiviral activities; affecting the immune and nervous systems, and other miscellaneous mechanisms of action. Mar. Drugs 2013, 11, 2510-2573. [CrossRef] [PubMed]

3. Luesch, H.; Yoshida, W.Y.; Moore, R.E.; Paul, V.J.; Corbett, T.H. Total Structure Determination of Apratoxin A, a Potent Novel Cytotoxin from the Marine CyanobacteriumLyngbyamajuscula. J. Am. Chem Soc. 2001, 123, 5418-5423. [CrossRef] [PubMed] 
4. Gutierrez, M.; Suyama, T.L.; Engene, N.; Wingerd, J.S.; Matainaho, T.; Gerwick, W.H. Apratoxin D, a potent cytotoxic cyclodepsipeptide from papua new guinea collections of the marine cyanobacteria Lyngbya majuscula and Lyngbya sordida. J. Nat. Prod. 2008, 71, 1099-1103. [CrossRef] [PubMed]

5. Matthew, S.; Schupp, P.J.; Luesch, H. Apratoxin E, a cytotoxic peptolide from a guamanian collection of the marine cyanobacterium Lyngbya bouillonii. J. Nat. Prod. 2008, 71, 1113-1116. [CrossRef] [PubMed]

6. Masuda, Y.; Suzuki, J.; Onda, Y.; Fujino, Y.; Yoshida, M.; Doi, T. Total synthesis and conformational analysis of apratoxin C. J. Org. Chem. 2014, 79, 8000-8009. [CrossRef] [PubMed]

7. Soria-Mercado, I.E.; Pereira, A.; Cao, Z.; Murray, T.F.; Gerwick, W.H. Alotamide A, a novel neuropharmacological agent from the marine cyanobacterium Lyngbya bouillonii. Org. Lett. 2009, 11, 4704-4707. [CrossRef] [PubMed]

8. Liu, L.; Rein, K.S. New Peptides Isolated from Lyngbya Species: A Review. Mar. Drugs 2010, 8, $1817-1837$. [CrossRef] [PubMed]

9. Matinkhoo, K.; Pryyma, A.; Todorovic, M.; Patrick, B.O.; Perrin, D.M. Synthesis of the Death-Cap Mushroom Toxin alpha-Amanitin. J. Am. Chem. Soc. 2018, 140, 6513-6517. [CrossRef] [PubMed]

10. Hu, W.; Zhang, F.; Xu, Z.; Liu, Q.; Cui, Y.; Jia, Y. Stereocontrolled and efficient total synthesis of (-)-stephanotic acid methyl ester and (-)-celogentin C. Org. Lett. 2010, 12, 956-959. [CrossRef] [PubMed]

11. Ren, R.-G.; Li, M.; Si, C.-M.; Mao, Z.-Y.; Wei, B.-G. Studies toward asymmetric synthesis of leiodelide A. Tetrahedron Lett. 2014, 55, 6903-6906. [CrossRef]

12. Bosch, L.; Mola, L.; Petit, E.; Saladrigas, M.; Esteban, J.; Costa, A.M.; Vilarrasa, J. Formal Total Synthesis of Amphidinolide E. J. Org. Chem. 2017, 82, 11021-11034. [CrossRef] [PubMed]

13. Lin, L.; Romano, C.; Mazet, C. Palladium-Catalyzed Long-Range Deconjugative Isomerization of Highly Substituted alpha,beta-Unsaturated Carbonyl Compounds. J. Am. Chem Soc. 2016, 138, 10344-10350. [CrossRef] [PubMed]

14. Menche, D.; Hassfeld, J.; Li, J.; Mayer, K.; Rudolph, S. Modular total synthesis of archazolid A and B. J. Org. Chem. 2009, 74, 7220-7229. [CrossRef] [PubMed]

15. Takano, D.; Nagamitsu, T.; Ui, H.; Shiomi, K.; Yamaguchi, Y.; Masuma, R.; Kuwajima, I.; Ōmura, S. Total Synthesis of Nafuredin, a Selective NADH-fumarate Reductase Inhibitor. Org. Lett. 2001, 3, 2289-2291. [CrossRef] [PubMed]

16. Chen, K.; Xu, Z.; Ye, T. Total synthesis of amphidinins E, F and epi-amphidinin F. Org. Chem. Front. 2018, 5, 629-632. [CrossRef]

17. ElMarrouni, A.; Joolakanti, S.R.; Colon, A.; Heras, M.; Arseniyadis, S.; Cossy, J. Two concise total syntheses of (-)-bitungolide F. Org. Lett. 2010, 12, 4074-4077. [CrossRef] [PubMed]

18. Brun, E.; Bellosta, V.; Cossy, J. Synthesis of the Acyclic Carbon Skeleton of Filipin III. J. Org. Chem. 2016, 81, 8206-8221. [CrossRef] [PubMed]

19. Rychnovsky, S.D.; Rogers, B.N.; Richardson, T.I. Configurational Assignment of Polyene Macrolide Antibiotics Using the $\left[{ }^{13} \mathrm{C}\right]$ Acetonide Analysis. Acc. Chem. Res. 1998, 31, 9-17. [CrossRef]

20. Huang, W.; Ren, R.G.; Dong, H.Q.; Wei, B.G.; Lin, G.Q. Diverse synthesis of marine cyclic depsipeptide lagunamide A and its analogues. J. Org. Chem. 2013, 78, 10747-10762. [CrossRef] [PubMed]

21. Kaneda, M.; Sueyoshi, K.; Teruya, T.; Ohno, H.; Fujii, N.; Oishi, S. Total synthesis of odoamide, a novel cyclic depsipeptide, from an Okinawan marine cyanobacterium. Org. Biomol. Chem. 2016, 14, 9093-9104. [CrossRef] [PubMed]

22. Babu, V.S.; Zhou, Y.; Kishi, Y. Design, synthesis, and cytotoxicity of stabilized mycolactone analogs. Bioorg. Med. Chem. Lett. 2017, 27, 1274-1277. [CrossRef] [PubMed]

23. O'Neil, G.; Black, M. A Synthesis of the C3-C15 Fragment of the Archazolids. Synlett 2009, 2010, 107-110. [CrossRef]

(C) 2018 by the authors. Licensee MDPI, Basel, Switzerland. This article is an open access article distributed under the terms and conditions of the Creative Commons Attribution (CC BY) license (http:/ / creativecommons.org/licenses/by/4.0/). 